(C) 2015, Elsevier. Licensed under the Creative Commons Attribution-NonCommercial-NoDerivatives 4.0 International

http://creativecommons.org/licenses/by-nc-nd/4.0/

\title{
Measures of process harmonization
}

\author{
H.L. Romero ${ }^{1}$, R.M. Dijkman ${ }^{1 *}$, P.W.P.J. Grefen ${ }^{1}$, A.J. van Weele ${ }^{1}$, A. de Jong ${ }^{2}$ \\ ${ }^{1}$ Eindhoven University of Technology \\ ${ }^{2}$ Aston University \\ School of Industrial Engineering \\ Aston Business School
}

P.O. Box 513, Eindhoven, The Netherlands

Birmingham, West Midlands, United Kingdom

\begin{abstract}
Context: Many large organizations juggle an application portfolio that contains different applications that fulfill similar tasks in the organization. In an effort to reduce operating costs, they are attempting to consolidate such applications. Before consolidating applications, the work that is done with these applications must be harmonized. This is also known as process harmonization.

Objective: The increased interest in process harmonization calls for measures to quantify the extent to which processes have been harmonized. These measures should also uncover the factors that are of interest when harmonizing processes. Currently, such measures do not exist. Therefore, this study develops and validates a measurement model to quantify the level of process harmonization in an organization.
\end{abstract}

Method: The measurement model was developed by means of a literature study and structured interviews. Subsequently, it was validated through a survey, using factor analysis and correlations with known related constructs.

Results: As a result, a valid and reliable measurement model was developed. The factors that are found to constitute process harmonization are: the technical design of the business process and its data, the resources that execute the process, and the information systems that are used in the process. In addition, strong correlations were found between process harmonization and process standardization and between process complexity and process harmonization.

Conclusion: The measurement model can be used by practitioners, because it shows them the factors that must be taken into account when harmonizing processes, and because it provides them with a means to quantify the extent to which they succeeded in harmonizing their processes. At the same time, it can be used by researchers to conduct further empirical research in the area of process harmonization.

Keywords: harmonization, business process, hierarchical measurement model, partial least squares 


\section{Introduction}

Many organizations have multiple applications that support similar tasks in the organization. Clearly, this is an undesirable situation. On the one hand, because (higher) license fees have to be paid to multiple software vendors. On the other hand, because the benefits of having information consolidated in a single place are forfeited. For example, often organizations do not know which products are bought or sold by multiple organizational units, because that information is not stored in the same system and the products do not have the same product codes. If they had that information, they could achieve economies of scale. In an attempt to remedy this situation, organizations are consolidating their application portfolio (Riempp \& Gieffers-Ankel, 2007). However, to consolidate the applications that are being used in the organization, the work that is done with these applications must also be harmonized (Sedera \& Dey, 2007). This is known as process harmonization. Process harmonization is the activity of designing and implementing business process standards across different regions or units, so as to facilitate achieving the targeted business benefits arising out of standardization, while ensuring a harmonious acceptance of the new processes by the different stakeholders (Fernandez and Bhat 2010, p.368). These benefits include the ability to re-use information systems between different processes and departments that work partly in the same manner. It is important to note the relation, but also the difference between process standardization and harmonization that are implied by this definition. Processes harmonization aims to implement process standards, same as process standardization. However, standardization strives for uniformity of processes, while harmonization allows for more variation to ensure harmonious acceptance of the standard (Richen and Steinhorst, 2005). We will discuss the relations and differences between standardization and harmonization in more detail in Section 2.

The increased interest in process harmonization has been expressed in theoretical efforts: (1) by researchers explaining the concept, and (2) by practitioners describing methodologies to harmonize business processes. However, these theoretical efforts do not identify performance measures to evaluate the extent to which process harmonization was achieved. Nor do they investigate further links with the improvements that are achieved as results of harmonization efforts. Still, performance measurement is of critical importance for organizational management (Dess and Robinson, 1984). At a process level, measurements provide information to control and manage processes in order to improve them. "Unmeasured and unchallenged performance does not improve" (Ebert, 2005). Given the importance of process harmonization in process improvement as has been attributed in the literature (Foster and Herndon, 1997; Hammer, 1990), there is a need for measures to evaluate to what extent processes are harmonized (i.e. to what extent standards were implemented). 
Therefore, the aim of this study is to develop and validate a set of operational measures to evaluate the level of harmonization of business processes in an organization. This set of operational measures is useful for two main reasons: First, researchers can use them to develop normative theory based upon empirical investigation of process harmonization; and second, practitioners can use them as a mechanism for making informed decisions about specific actions to take with respect to the harmonization of processes and to gain insight into the results of those actions. Measures provide direction of which aspects of the process harmonization can be improved.

Based on this motivation, the main research question to be addressed by this study has two parts:

G1: What factors influence the level of process harmonization of business processes in an organization; and

G2: What measures can be used to evaluate the level of harmonization of business processes in an organization?

An integral approach for construct measures and validation procedures has been followed to achieve the goal of this study. It is based on the approaches proposed by Churchill (1979) and MacKenzie et al. (2011). It is divided in two phases: an exploratory phase and a confirmatory phase. The approach uses different methods for data collection, including literature review, interviews with experts, workshops and an online survey, to gather different views of the concept. Our study extends the extant literature by developing a higher order construct, taking into account the most recent insights in the academic literature about how to correctly specify higher order constructs, using a Partial Least Squares (PLS) analysis (Becker et al. 2012; Ringle et al. 2012).

The remainder of this document is organized as follows. Section 2 introduces the concept of process harmonization in more detail. It also introduces the related concepts of process standardization and process complexity and the relation between these concepts. Section 3 presents an overview of the methodology followed to conduct this study. Section 4 presents the analysis of the data and intermediate results and Section 5 presents the final results. Section 6 presents the conclusions, limitations and future work.

\section{Application Consolidation, Process Harmonization and Related Concepts}

Application consolidation is the effort of reducing the number of applications in the organizations that perform similar tasks (Riempp \& Gieffers-Ankel, 2007). Since applications, and especially ERP systems, support the business processes of an organization, this requires that those processes are also 
consolidated (Sedera \& Dey, 2007). One of the ERP systems that explicitly identifies the relation between ERP and processes is SAP, which provides a collection of processes that are supported by the system (Curran \& Keller, 1999).

Process harmonization is the activity of aligning different variants of a family of processes, by capturing their commonality and variability in a consolidating and efficient manner, without attempting to make different processes identical. Harmonization accepts that different stakeholders in an organization have different, possibly conflicting, requirements for a process, depending on their context. This means that, when harmonizing processes, differences between the process variants for which there is no particular reason should be resolved, while differences for which there is a reason can remain. Different conceptualizations of process harmonization have been adopted in the literature (Fernandez and Bhat, 2010; Schäfermeyer et al., 2010; Wüllenweber et al., 2008). A precise specification of what we mean by process harmonization is dependent on the research stream that we decide to adopt. In this section two opposite research streams are discussed to derive a systematic and theoretical basis for process harmonization. The first stream consists of literature in which process harmonization is treated as similar to process standardization at a local level, across different locations, regions or organizational units. For instance, Fernandez and Bhat (2010, p.368) defined process harmonization as "the activity of designing and implementing business process standards across different regions or units, so as to facilitate achieving the targeted business benefits arising out of standardization, whilst ensuring a harmonious acceptance of the new processes by the different stakeholders". In this stream, standardization is defined in a broader sense in which local standards can also be the result of standardization efforts. In contrast, the second stream distinguishes differences in goals between harmonization and standardization. In this stream, the goal of process standardization is to achieve uniformity of process activities across the value chain and across firm boundaries (Wüllenweber et al. 2008, pp.2011-2012), while the goal of harmonization is to align similar processes based on a single, focused business objective (Hufgard and Gerhardt 2011, p.169). However, when analyzing the differences between harmonization and standardization as they are discussed in these two streams, we notice that differences only exist with respect to strict standardization. In this strict view, standardization leads to a single unified process that does not allow variability (Richen and Steinhorst, 2005). However, in a more broad view, local variations on the standard process are also allowed. Therefore, we claim that harmonization and standardization are similar concepts that differ only with respect to their focus: standardization stresses the unification of processes, while harmonization stresses a trade-off between global unification and local variation.

As an example, Figure 1 shows two tendering processes that could run in the same company, supported by different software applications. The processes are similar, but contain differences as 
well. The differences exist with respect to the tasks that are performed, their labels, the order in which the tasks are performed, and with respect to the level of authorization that the internal customer has. In particular, the second process variant includes a market survey that the first variant does not have and the order in which the 'Prepare RFP' and 'Define eval. criteria' are performed differ. Also, the labels of the 'check invitation' and 'receive invitation' tasks differ, hinting that slightly different activities that are being performed in these tasks. The evaluation of the received offers is performed differently between the variants, both concerning the evaluation done by the procurement department and concerning the evaluation done by the internal customer. In the first variant, the internal customer can evaluate all options on the short list, but in the second variant, the internal customer can only approve the selection that is made by the procurement department.

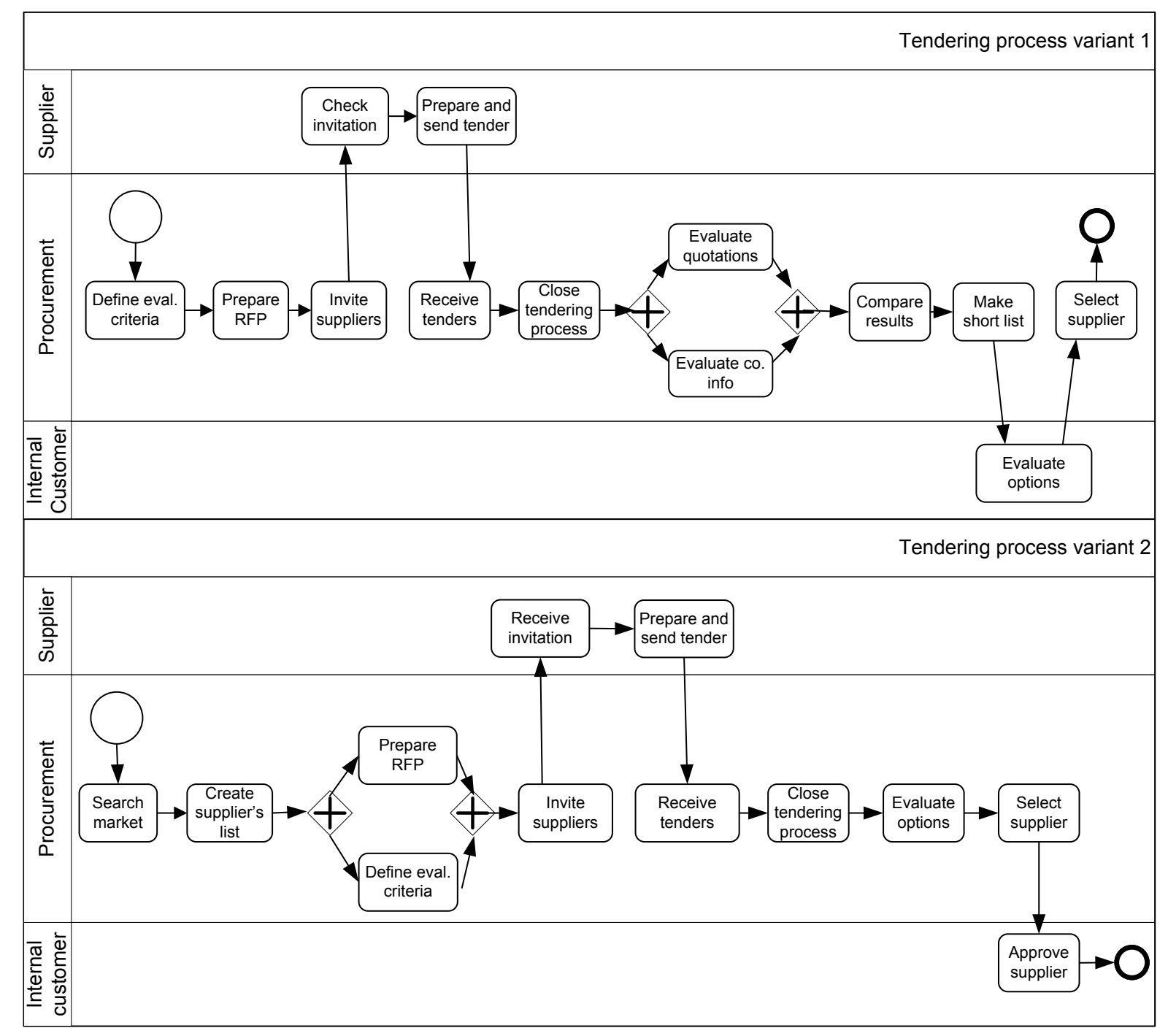

Figure 1. Multiple variants of the same process.

In order to consolidate the applications that support the two processes, the differences between the variants from Figure 1 need to be resolved. According to our definitions of standardization and 
harmonization, when fully standardizing the process variants, all differences must be resolved. However, when harmonizing the variants, certain differences may be kept if there is good reason to do so. For example, it may be necessary for cultural or legal reasons to keep the differences in the way in which the offers are evaluated. This would, of course, also have implications for the supporting software applications, because those would also need to support the different variants.

Measures for process harmonization can be used to determine the extent to which harmonization has been achieved. In related work, there exist measures that can be used to determine the level of similarity between processes (Dijkman et al., 2011) and to identify differences between processes (Küster et al., 2008). These measures could also be used to measure the extent to which harmonization has been achieved, because more similar process variants can be assumed to be more harmonized. However, measuring process similarity may require a lot of effort, because it requires that models are created for the processes. Also, applying the measures themselves either involves complex manual work or requires that the processes are defined in a tool that supports similarity measurement. For research purposes, a more lightweight measurement model that is more directly applicable is more useful, which is why we aim to develop such a measure in this paper. The measurement model that we envision can be applied through questionnaires answered by process managers within a short timeframe, containing questions like: "The activities that we perform in different process variants are: very dissimilar, dissimilar, not dissimilar/not similar, similar, very similar". While less precise than measuring process similarity, this is also less time consuming. It should also be noted that evaluating the similarity or difference of process models is not the same as evaluating the similarity of the processes themselves. Process models are merely a representation of the processes. In practice, the execution of the processes often deviates from the process models (Rozinat \& van der Aalst, 2008). This paper focuses on developing a measurement tool for analyzing the level of harmonization of the processes as they are executed, using a lightweight measurement tool that can be applied by a practitioner within a short timeframe.

\section{Methodology}

This study adopts an integral approach in developing a measurement model for process harmonization, based on the procedures proposed by Churchill's (1979) and Mackenzie et al.(2011). The process is depicted in Figure 2 and is divided in two phases, an exploratory phase and a confirmatory phase. The goal of the exploratory phase is to build a model for measuring the level of harmonization of a business process. The confirmatory phase validates the measurement model. The steps that constitute the research method are explained in detail in this section, while the results of the steps are explained in Section 4. 


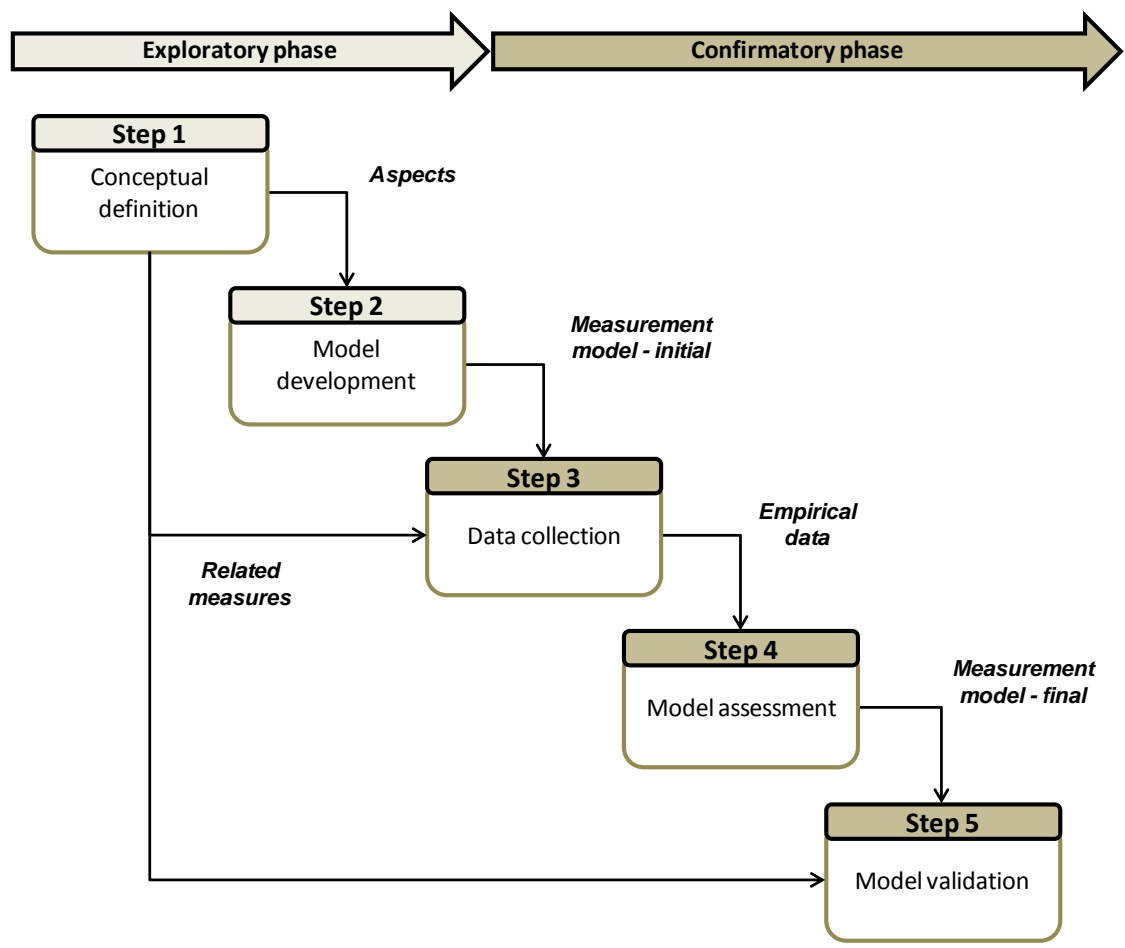

Figure 2. Procedure for developing measures of process harmonization

\subsection{Conceptual definition}

First, we derived a set of aspects of process harmonization as well as related measures (in particular standardization and complexity) by means of a literature review. The literature review was conducted in five steps: a pre-search, a systematic search, a cross-reference search, a selection step, and a classification step.

A pre-search was conducted using Google Scholar, to determine the keywords to be used for the systematic search. Google Scholar was chosen, considering that it has a broad scope. Using the keyword "harmonization" only a limited number of articles are found, and very few specifically focused on process harmonization. The keyword "process standardization" was also used for the presearch considering the overlap with this concept as explained in detail in Section 2. When adding this keyword a high number of papers are retrieved as shown in Appendix A. Based on this pre-search, we identified additional keywords that were strongly related to "process harmonization" and "process standardization". These keywords are also shown in Appendix A.

A systematic search was conducted, using the keywords that were identified in the pre-search step and three search engines: ABI/INFORMS, EMERALD and SPRINGER. These search engines were used, 
because they cover most of the high-quality journals and conferences in the area of interest. A preselection of the articles was performed looking for keywords in the title or abstracts of the papers retrieved.

A cross-reference search was performed using a backward tracing technique, after completing the first search cycle and selecting a set of articles using the selection criteria specified in Appendix A.

Selection of the articles was done by inspecting the title and abstract to separate the potentially relevant articles from the obviously irrelevant studies, using the relevance and general criteria described in Appendix A. After the irrelevant articles were discarded, the articles were evaluated using the quality criteria also described in Appendix A. This evaluation was conducted by reading the method, analysis and conclusion sections.

We classified the aspects of process harmonization by searching for phrases or words in the text of the documents collected, to capture the contextual meaning of the concept as suggested in Strauss and Corbin (1998), leading to an initial set of aspects and a collection of related measures.

Second, a workshop was held with practitioners to contrast and complete the set of aspects found in literature with the opinions of practitioners. The workshop included seven participants organized in two mixed groups with in total three academics and four practitioners. The practitioners all were business unit managers who had participated in a process harmonization project for their business unit. Participants were asked to identify aspects of process harmonization that exert an influence on the extent of harmonization of a process. Aspects that are both found in literature and identified as relevant to the practitioners were included in as relevant aspects for the measurement model.

\subsection{Model development}

After determining the relevant aspects, measures were defined that enabled measuring the extent to which each individual aspect was harmonized.

Firstly, interviews were conducted using a questionnaire with open questions to identify specific measures that have been used in companies involved in harmonization initiatives, to evaluate their level of harmonization improvements. Interviewees were also asked about the motivation and expected benefits when conducting these initiatives, to identify which measures are significant in practice. Interviews were conducted with two experts engaged in harmonization projects in large scale companies and three academics. One expert is a professional responsible to conduct a large scale 
harmonization project in a governmental organization in the last six years. The other expert conducted a study about the impact of factors such as information technology in process standardization versus harmonization in value chain management. This study included six multinational companies, in which two of them show successful results in their harmonization efforts.

Secondly, a meeting with academics was performed for brainstorming about ideas of more measures aligned with those gathered in practice. The original list of measures was rewritten to guarantee that its wording was simple and precise, as suggested in the literature by Tourangeau et al. (2000). This process was not exhaustive because it was only intended to generate a first set of measures which allows a quantitative validation of the aspects proposed. The academics are participating in a project of process harmonization and were exposed to literature and practical experiences in the topic. This group of professionals and academic experts was selected considering their experience, to identify indicators of process harmonization that they have seen in practice in the companies studied and in previous literature on the topic.

Thirdly, a hierarchical (second order) measurement model was build using the measures derived in the previous steps. Our measurement model was specified as a hierarchical factor model type II (reflective first order and formative second-order). The second order construct is process harmonization, and the first order constructs are the relevant aspects defined before. Measures are assigned to one specific aspect that they assessed. Our measurement model is the initial hierarchical (second-order) model that will be empirically tested and validated in the confirmatory phase. It was a design decision to build the model as hierarchical instead of considering that all the indicators are just part of one concept. The advantage of our model is that it provides more direction to researchers and practitioners about the specific aspects of harmonization that they need to focus on in order to achieve the expected improvements.

\subsection{Data collection}

An online survey was conducted to identify how much the current set of measures actually reflects different aspects of process harmonization. The survey instrument used is included in Appendix B and it required around 20 minutes for completion. It was built using a Google document and the link for access was distributed to the targeted respondents.

The targeted respondents for the online survey were professionals with experience in business process management (BPM) practices. The survey instrument prepared was distributed in two languages: English and Dutch, targeting a different group of professionals within BPM. The Dutch questionnaire was sent to members of the BPM round table at Eindhoven University of Technology, with more than 
300 members registered when the survey was conducted. The questionnaire translated to English was distributed throughout BPM experts worldwide invited through advertisements made on LinkedIn in a group called BPMInstitute.org with 1,311 members. It was also published through an internal communication portal used in an international consultancy firm in the Netherlands (with 1,779 members registered). Professionals in BPM assumed the role of key informants because they provide information on an aggregate unit of analysis (in this case a harmonization project) by reporting on organizational characteristics (Dillman, 2011).

A set of criteria described in Dillman (2011) were considered to design the questionnaire. This set of criteria focuses on reducing the sources of error when conducting survey research, to be able to generalize sample results to a defined population. The sources of error include: coverage error, sampling error, measurement error and non-response error. A coverage error is "the result of all units in a defined population not having a known nonzero probability of being included in the sample drawn to represent the population". The sampling error is "the result of surveying a sample of the population rather than the entire population". A measurement error is "the result of inaccurate responses that stem from poor question wording, poor interviewing, survey mode effects and/or some aspect of the respondent's behavior". A non-response error is "the result of no response from people in the sample, who, if they had responded, would have provided different answers to the survey questions than those who did respond to the survey". Table 1 summarizes decisions made to reduce the sources of error described when designing the survey instrument, following recommendations described in the literature (Crawford et al, 2001; Couper et al, 2001; Dillman, 2011).

In the survey two constructs were evaluated: business process standardization and business process complexity. Measures of these two concepts can be seen as reflective measures of process harmonization, because if the level of harmonization increases we can expect that the level of standardization also increases while the process complexity decreases. They were operationalized using instruments provided in the literature and depicted in Appendix C. Business process standardization (BPS) was operationalized using a 3-item instrument provided by Münstermann et al.(2010), which was selected in Step 1 to be used for further validation. The second construct operationalized is business process complexity (BPC). Schäfermeyer et al.(2012) define business process complexity as the level of difficulty reported by project managers and operators, during process standardization or execution. They operationalized it with a 5-item instrument, which we use in our survey.

After the survey questionnaire was complete, a pre-test was conducted. The questionnaire used for the pre-testing is included in Appendix D. After the results of the pre-test were collected, the survey 
questions were further improved and an additional check was performed but only with informal experts' interviews. The online survey was sent with a reminder two weeks later, to increase the respondent rate. The data was collected after four weeks for further analysis.

Table 1. Actions to reduce the sources of error in data collection

\begin{tabular}{|c|c|}
\hline Type of error & Actions \\
\hline $\begin{array}{l}\text { Coverage } \\
\text { error }\end{array}$ & $\begin{array}{l}\text { - Promoted the survey through a group called BPMInstitute.org using a } \\
\text { social network (LinkedIn). } \\
\text { - Did not use a password or type of authorization to facilitate access to } \\
\text { the survey. }\end{array}$ \\
\hline $\begin{array}{l}\text { Sampling } \\
\text { error }\end{array}$ & $\begin{array}{l}\text { - Selected three big communities of BPM professionals: BPM round } \\
\text { table (300 members), BPMInstitute.org (1,313 members) and } \\
\text { professionals from an international consultancy firm in The } \\
\text { Netherlands (with } 1,779 \text { members registered). } \\
\text { - Sent invitation online with a link to access the survey. } \\
\text { - Sent a reminder to fill the questionnaire, two weeks after the initial } \\
\text { invitation. } \\
\text { - Gathered results four weeks after the first invitation. } \\
\text { - Translated questionnaire in English and Dutch, to avoid excluding a } \\
\text { significant portion of the population for language barriers. }\end{array}$ \\
\hline $\begin{array}{l}\text { Measurement } \\
\text { error }\end{array}$ & $\begin{array}{l}\text { - Pre-tested the survey with six academics with expertise in BPM and } 2 \\
\text { in survey research using cognitive interviewing (Collins, 2003). } \\
\text { - Included questions to check whether respondent understood the } \\
\text { question and provided an appropriate answer. }\end{array}$ \\
\hline $\begin{array}{l}\text { Non- } \\
\text { response } \\
\text { error }\end{array}$ & $\begin{array}{l}\text { - Prepared an invitation to fill the questionnaire including the goal of } \\
\text { this study, a description of our contribution to future research, and } \\
\text { practical implications. }\end{array}$ \\
\hline
\end{tabular}




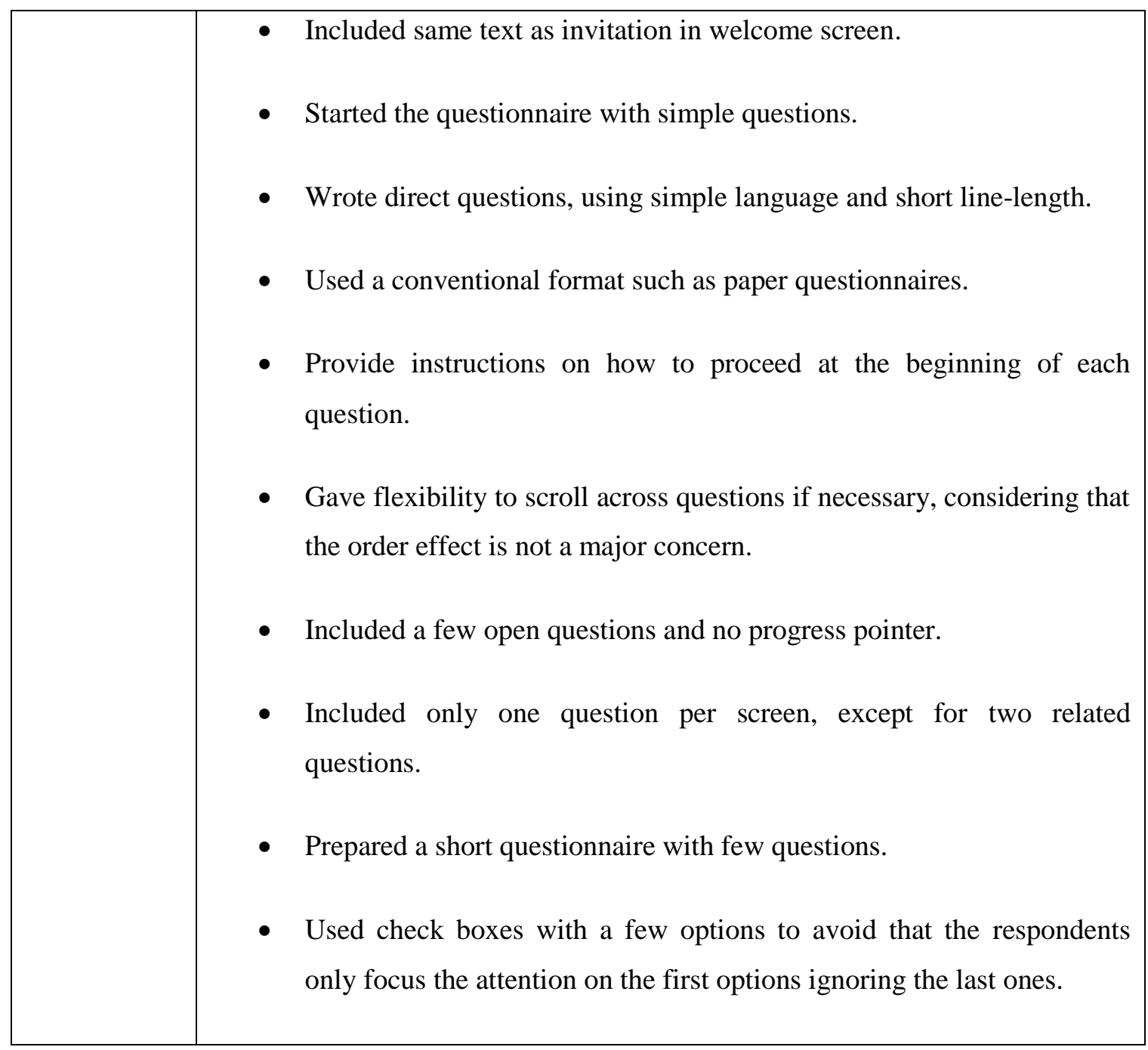

Finally, when the data was collected we assumed that responses from people who did not participate in the survey are no different than those who did participate. This assumption was represented using the following hypothesis, where $\mu$ represents the mean value of a group of observations in the sample:

$\mathrm{H}_{0}: \mu_{\text {respondents } 1}=\mu_{\text {No-respondents } 2}$

$\mathrm{H}_{1}: \mu_{\text {respondents } 1} \neq \mu_{\text {No-respondents } 2}$

This assumption was tested conducting a non-response bias analysis to evaluate the extent to which our sample represents the population of this study and the biases observe in the responses due to nonresponse (Armstrong and Overton, 1977). An extrapolation method was carried over successive waves of the survey. We identified two waves of questionnaire returns. Respondents in the first (early) wave are those who replied after the survey was made available for the first time. The second (late) wave includes respondents who replied after a reminder was sent, two weeks after the first invitation to fill the survey. 
The analysis includes the comparison of descriptive statistics of the demographic data and comparison of key variables (Sheikh and Mattingly, 1981; Etter and Perneger, 1997). The demographic considered were: the origin of respondents divided per language (Dutch and International sample), the experience in process harmonization projects (yes/no, and the time of experience), and the role of respondents in harmonization projects. The key variables include the indicators of process harmonization evaluated in the survey and the comparison was conducted using an independent sample two-tailed T-test with a level of significance of 0.05. We compared differences in their perception about the extent to which the indicators derived in our measurement model actually reflect the level of harmonization of a process. Additionally, we evaluate that the assumptions of the T-test were met using Levene's Test for Equality of Variances. In both tests, two paired T-test and Levene's test, the null hypothesis can be rejected if the p-value calculated is smaller than 0.05 .

\subsection{Model assessment}

Factor analysis was used in this step to suggest the number of dimensions underlying the level of harmonization of a business process. Data collected in the previous step was used as an input for factor analysis. It consisted of responses gathered from 119 professionals in BPM, using both the Dutch and English questionnaire. The answers provided were their opinion based on previous experience or knowledge on the topic. They evaluated to what extent the provided measures actually assess an aspect specific of process harmonization. Their input was provided using a Likert scale from 1 until 5.

Content validity of the items generated and the dimensionality of the construct under study are evaluated using exploratory factor analysis (EFA), which is conducted using the software package for statistical analysis (SPSS). Five steps were followed to conduct this exploratory factor analysis as suggested by Hair et al.(2006): (1) Examine the factor loading matrix; (2) identify significant loadings in the matrix; (3) assess communalities; (4) Re-specify the factor model if needed; and (5) Label the factors.

There are three EFA decisions which are very important for the outcome of the analysis: (a) the factor extraction model used; (b) the number of factors retained; and (c) the method used to rotate factors, if more than one factor is retained (Conway and Huffcutt, 2003). Common factor analysis is the factor extraction model selected. It is more appropriate than the component factor analysis considering that the goal of this step is to identify latent dimensions represented in the original variables and we do not have previous knowledge about the amount of specific of error variance (Hair et al., 2006).

The number of factors to retain was based on the following three criteria: (1) The latent roots or eigenvalues should be greater than 1 ; (2) The conceptual foundation, indicating the underlying 
dimensions of the concept based on the theory; And, (3) the scree test criterion, which indicates the maximum number of factors that must be retained as the value where the inflexion point occurs. An orthogonal rotational method was selected to rotate factors. Varimax was the method selected because it "has proved successful as an analytical approach to obtaining an orthogonal rotation of factors" (Hair et al., 2006).

\subsection{Model validation}

In this step the internal consistency and reliability of the initial model is assessed. In addition to internal consistency and reliability, we also evaluated whether our model behaves as expected with respect to related concepts.

In literature, process harmonization is strongly related to both process standardization (as discussed in detail in Section 2) and to process complexity (Schäfermeyer et al., 2010). Process complexity is defined as the extent to which cases of a process deviate from each other. If different cases are expected to be executed in a strongly similar manner, such as in a cell-phone subscription process, a process is considered to have low complexity. If different cases are expected to be executed in a strongly different manner, such as in a creative process, a process is considered to have high complexity.

Consequently, a valid measurement model for process harmonization should show a strong correlation between process harmonization and both process standardization and process complexity, as they are measured using their own existing measurement models. Therefore, the following hypotheses should hold:

H1: organizations that have a more harmonized processes, have a more standardized process.

H2: organizations that have less complex processes, have more harmonized processes.

Note that we postulate these hypotheses not to test them themselves; we know them to be true either by definition, or because others investigated them (Schäfermeyer et al., 2012). Rather, we use hypotheses that we know to be true to validate our measurement model. If the hypotheses indeed hold, this is an indication of the correctness of our measurement model.

Data of the related concepts previously defined (process standardization and process complexity) was also collected in the online survey of the previous step. Partial least square (PLS) was chosen for the analysis of this measurement model for three reasons: (1) it makes fewer demands regarding sample size than other methods; (2) It is able to handle both formative and reflective indicators; and (3) it is better suited for theory development than for theory testing. Smart PLS software was used to measure the scale of measurement of the first and second order constructs. 
The repeated indicator approach with mode B on the process harmonization construct and inner path weighting scheme is used to estimate the hierarchical latent variable model (Becker et al, 2012). This approach consists of using the indicators twice: (1) for the first-order constructs and (2) for the second-order construct $(\mathrm{BPH})$. Having specified the measurement model in this way, the path coefficients between the first and second order constructs represent the loadings of the second order latent variable (Löhmoller, 1989; Becker et al., 2012). "This approach produces generally less biased, and therefore, more precise parameter estimates and a more reliable higher-order construct score" (Becker et al, 2012).

The evaluation of the measurement model include: (1) an assessment of the first-order reflective constructs using the constructs and measures loadings, t-values, AVE, composite reliability and discriminant reliability; and (2) for the second order formative construct, an evaluation of the measures weights, significance of weights and multicollinearity among measures. The evaluation of the convergent validity is done using the using the constructs and measures loadings and weights and t-values. The values of factor loadings and AVE should be above 0.50 and composite reliability above 0.70 (Hair et al., 2006). The discriminant validity for the first-order constructs is evaluated following the criterion described by Fornell and Larcker (1981). The criterion is that the square root of AVE should be greater than the variance shared between the construct and other constructs in the model (Bollen, 1998). The variance inflator factor (VIF) test was used to evaluate multicollinearity among measures, which is mostly used when using formative indicators (Ringle et al. 2012).

A nomological network is used to assess the validity of the multidimensional structure (MacKenzie et al., 2011). The direct effect of an antecedent of process harmonization on each aspect of the concept is measured. If they are equal, we consider this as a support of the multidimensional construct (Edwards, 2001). The antecedent construct selected in this study is business process complexity, using the construct provided by Schäfermeyer et al.(2012). The final endogenous construct used to build the nomological network is business process standardization, using the operationalization proposed by Münstermann et al. (2010). 
Table 2. Measures of process standardization and their evaluation

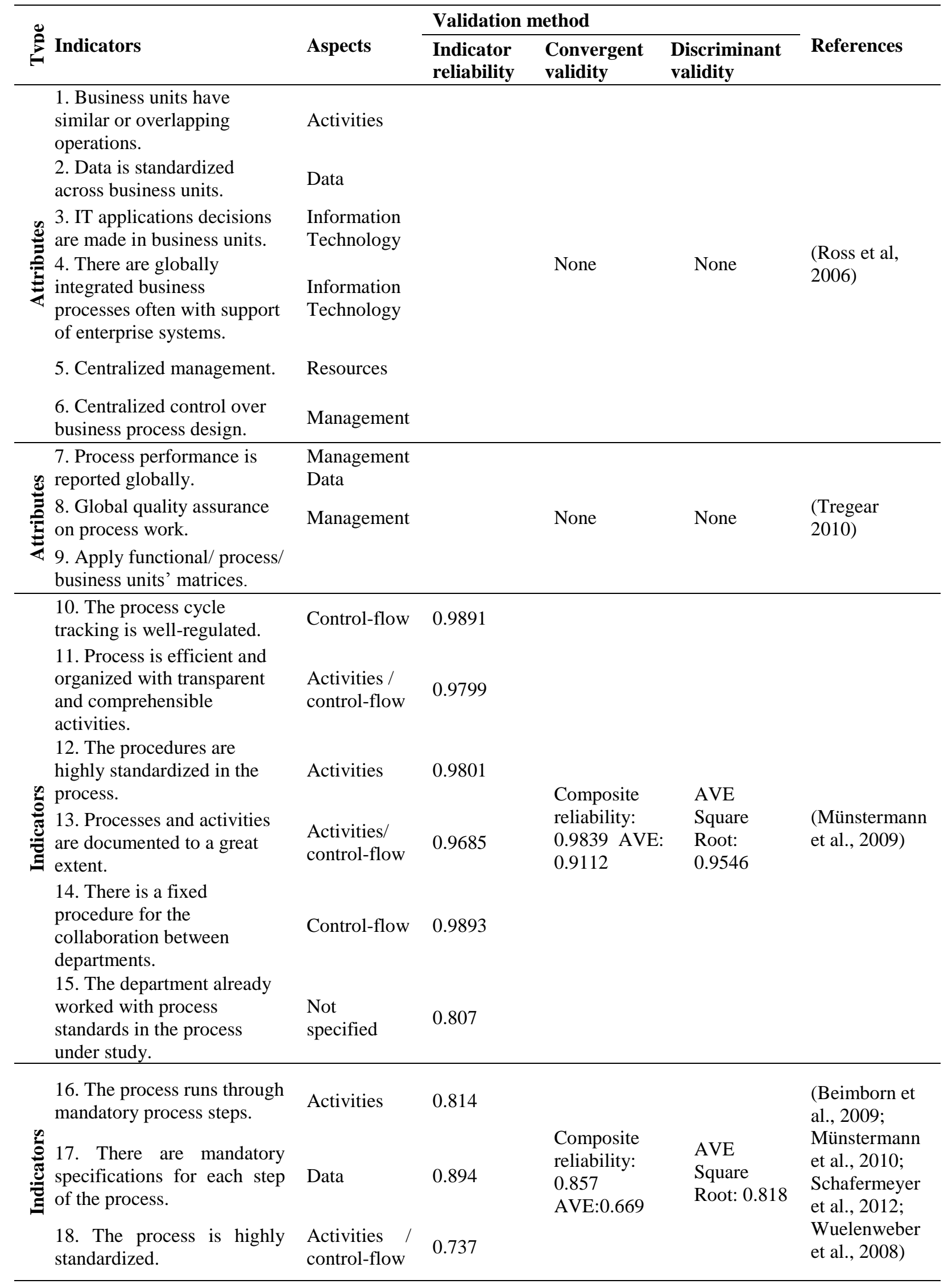




\section{Data analysis}

This section presents the analysis of the data as well as intermediate results. It is organized in four subsections that describe the results as they are depicted in Figure 2.

\subsection{Aspects}

Relevant aspects of process harmonization were identified in literature and a workshop with practitioners as explained in Section 3.1.

Table 2 shows the different measures and the aspects of business process standardization identified in the literature. It also includes the validation method used to assess the validity of these measures. The list of aspects includes: activities, control flow, data, information technology, management and resources. Activities refer to the level of standardization of specific steps in the process. Control-flow measures the level of standardization of the sequence of activities. Data measures the level of standardization of input and output data used in the process. Information Technology refers to the level of standardization of IT systems. Management measures the standardization of the process assessment. And resources refer to the level of standardization of human resources involved in the process.

The aspects derived from the literature were compared to those identified during the workshop. Aspects identified by at least two sources were included. As a consequence, only Management was excluded for further analysis. Activities and control-flow are considered as a single aspect, because in some cases it was not clear to what extent a measure evaluates an individual activity or the collection of activities with a predefined order.

\subsection{Initial measurement model}

After identifying the relevant aspects in this manner, measures were developed for each of the aspects in a brainstorm session with academics and interviews with practitioners, as explained in Section 3.2.

A first set of eight measures for the aspects of process harmonization was gathered and is depicted in Table 3. This initial set includes one indicator for activities (IA1), two related to Data aspect (ID1 and ID2), three defined for Information Technology (IT1, IT2 and IT3) and finally, two related to resources (IR1 and IR2). 
Table 3. Measures of process harmonization

\begin{tabular}{|l|l|l|}
\hline Aspect & ID & Measures \\
\hline Activities & IA1 & The percentage of common activities in the process. \\
\hline Data & ID1 & $\begin{array}{l}\text { The number of different documents used as input for the same } \\
\text { process. }\end{array}$ \\
\hline Data & ID2 & The number of different output reports. \\
\hline IT & IT1 & $\begin{array}{l}\text { The number of different software applications in used in the } \\
\text { process. }\end{array}$ \\
\hline IT & IT2 & $\begin{array}{l}\text { The number of different supplier's paid for the software } \\
\text { applications. }\end{array}$ \\
\hline IT & IT3 & The amount of money paid for the software applications. \\
\hline Resources & IR1 & The percentage of common roles in the process. \\
\hline Resources & IR2 & The number of different roles executing the same activity. \\
\hline
\end{tabular}

The measures that are shown in Table 3 have a relation to those from Table 2. Firstly, because the researchers who helped construct the measures from Table 3, used those from Table 2. Secondly, because the aspects from Table 3 were directly derived from those from Table 2 (and from the workshop results). Note, however, that the measures from Table 2 do not have equal validity, as some are validated while others are not. Consequently, one could argue that non-validated measures should not be carried over to the actual measurement model. We did not follow that argument, because we will evaluate the measurement model ourselves in the next step.

Using these measures we built a measurement model which evaluates the level of harmonization of a business process in an organization. This initial measurement model derived is depicted in Figure 3. It shows that the level of harmonization is composed by four different aspects as identified before (data, activities, resources and IT). Each one of these aspects is measured through a set of indicators. The indicators are represented as reflective because within each aspect, they are expected to be correlated. As a results, a hierarchical model (reflective first order (for DATA, Activities (ACT), Resources (RES) and IT) with a formative second order (business process harmonization-BPH) model was derived. 


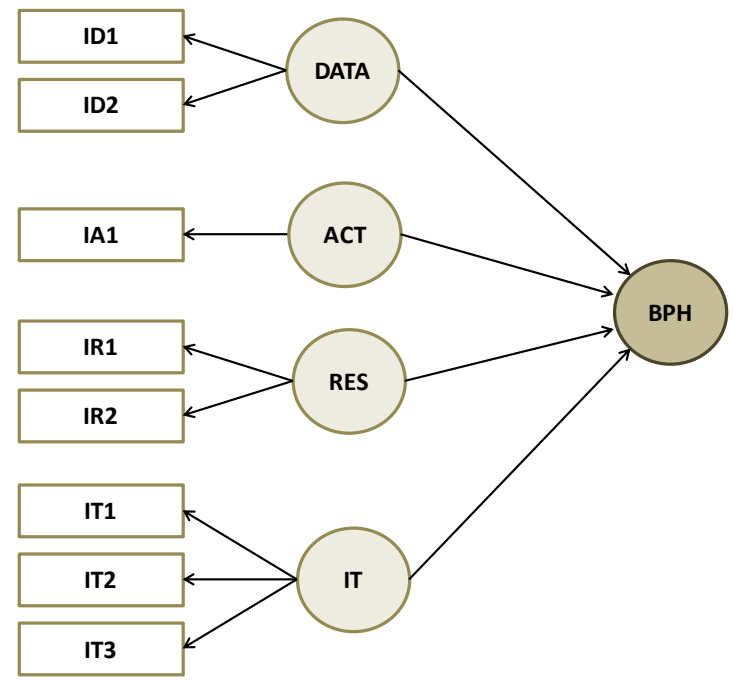

Figure 3. Initial hierarchical model (reflective first order and formative second order)

\subsection{Empirical data}

After developing the measurement model, it was validated by collecting data on its validity in a survey among practitioners, as explained in Section 3.3.

Table 4 shows the demographics of participants divided in two groups early and late respondents. For each possible answer, the table both shows the number of respondents in a particular group that gave that answer and the percentage of respondents that gave that answer. The table shows whether the respondent belongs to the Dutch sample or to the international (English) sample, whether the respondent personally has experience in a process harmonization project, how many years the respondent has experience with process harmonization and what the role of the respondent is.

In total, 119 responses were gathered. They are composed by sample groups: the Dutch sample and the International sample. The response rate for the Dutch sample is $16.7 \%$, with 50 complete surveys out of a targeted population of 300 members of the BPM round table by the time the survey was conducted; And $2.23 \%$ for the International sample with 69 responses out of a population of 3,092 members (1,313 form the LinkedIn community and 1,779 from an international consultancy company).

We distinguish between early and late respondents, because of the low response rate for the international sample. Determining the difference between early and late respondents allows us to draw conclusions about a potential response bias that this may imply. Our response rate of $16.7 \%$ in the Dutch sample slightly exceeds the $10-12 \%$ rate that Hambrick et al. (1993) describe as typical for 
surveys of executives. However, for the International sample this response rate was significantly reduced to $2.23 \%$. Even though the survey was implemented following guidelines such as Dillman (2011), we expected to obtain a low response rate due to the subject of the survey. A difficulty to obtain a higher response rate is that not everyone in the sampling frame may be familiar with the subject of the survey. They are professionals in business process management (BPM) but not necessarily focused on process harmonization within BPM. For the Dutch sample we have closer contact with the potential participants and have more control over their expertise in BPM, compared to the International sample. Therefore, potential respondents which are unfamiliar with the topic may not feel interested or uninformed to provide enough input to the survey.

Table 4. Participants demographics divided early and late respondents

\begin{tabular}{|l|l|l|l|l|l|}
\hline \multirow{2}{*}{ Demography } & \multirow{2}{*}{ Category } & \multicolumn{2}{|l|}{ Respondents (early) } & \multicolumn{2}{l|}{ Non-respondents (late) } \\
\cline { 2 - 6 } & & Number & Percentage & Number & Percentage \\
\hline Language & Dutch & 38 & 38,0 & 12 & 63,2 \\
\cline { 2 - 6 } & English & 62 & 62,0 & 7 & 36,8 \\
\hline \multirow{5}{*}{ Experience } & Yes & 53 & 53,0 & 13 & 68,4 \\
\cline { 2 - 6 } & No & 47 & 47,0 & 6 & 31,6 \\
\hline \multirow{5}{*}{ Role } & None & 47 & 47,0 & 6 & 31,6 \\
\cline { 2 - 6 } & Less than 1 year & 30 & 30,0 & 8 & 42,1 \\
\cline { 2 - 6 } & 1 to 3 years & 20 & 20,0 & 5 & 26,3 \\
\cline { 2 - 6 } & More than 3 & 3 & 3,0 & 0 & 0,0 \\
\hline & Project manager & 50 & 50,0 & 0 & 0,0 \\
\cline { 2 - 6 } & Manager & 2 & 2,0 & 4 & 21,1 \\
\cline { 2 - 6 } & Process architect & 20 & 20,0 & 4 & 21,1 \\
\cline { 2 - 6 } & Business analyst & 8 & 8,0 & 1 & 5,3 \\
\cline { 2 - 6 } & Consultant & 14 & 14,0 & 2 & 10,5 \\
\cline { 2 - 6 } & Other & 6 & 6,0 & 8 & 42,1 \\
\hline
\end{tabular}

Comparing the level of experience between both samples, we can observe that the percentage of people with experience in harmonization projects increased by $15 \%$ in the late response sample compared to the early response. However, the time of experience was reduced. It can be observed that in the late response sample none of the respondents had more than three years of experience. Significant differences were observed in terms of the role in both samples. The majority of early respondent were project managers while in the late response sample these group is distributed among managers and others. It is possible that the term project manager is too specific and therefore, several terms for managers with the same type of function can be used. However, in terms of the role we can conclude that significant differences are register in the early and late respondent's sample. 
After observing differences in demographic characteristics of both samples, we decided to evaluate to what extent these differences influence their responses. The descriptive statistics for all the responses are shown in Appendix E and Appendix F. Appendix E shows the descriptive statistics of each of the indicators collected for two groups (1- early and 2- late respondents). For each of the indicators, the mean, standard deviation and standard error mean was calculated. They are further used for the t-test.

The results depicted in Appendix $\mathrm{F}$ show that for all the indicators, the significance p-value) of Levene's test is greater than 0.05 , except for IT3 which is 0.007 . These results indicate that the assumption that the variances are equal cannot be rejected and therefore, a t-test. Only for IT3 we considered the results for equal variance not assumed. The results of the T-test for all the indicators show a p-value greater than 0.05 . Therefore, no significant differences are detected, and at 0.05 level of significance, the null hypothesis that early and late responses are not different $\left(\mathrm{H}_{0}: \mu_{\text {respondents } 1}=\mu_{\text {No- }}\right.$ respondents2) cannot be rejected, and we consider that there is no response bias in the results obtained.

Approximately half of the respondents indicated that they had no experience in a process harmonization project. This is not necessarily a threat to validity, because a respondent does not have to have participated in a process harmonization project to know what process harmonization is. However, further analysis is desirable. To do this analysis, we used the open question from the survey: 'what is harmonization according to you?' If most respondents answer this question correctly, we can assume that they have a general understanding of what process harmonization is. To analyze this, we took a sample of 40 respondents and checked whether their answer to this question was in line with: 'process harmonization harmonization is about making processes more similar/aligned/standard/uniform/...' Of the 40 respondents 37 (93\%) gave an answer along these lines. From this we conclude that the knowledge of the respondents is sufficient for reliable results.

The analysis is performed with 119 responses, which constitutes more than 14:1 ratio of observations per variable. This ratio is more than adequate, a minimum of 50 observations and 5:1 ratio (Hair et al, 2006), for the calculation of the correlations between variables. The overall measure of sampling adequacy (MSA) of 0.761 , and above 0.50 for each individual variable $(0.775,0.798,0.793,0.844$, $0.679,700,729$ and 840), indicate that sufficient correlation exists among variables and therefore it is appropriate to proceed with the factor analysis. An exploratory common factor analysis was conducted. Table 5 shows that the total variance can be explained by three factors which can explain $68.67 \%$ of the total variance. They also have an eigenvalue of 1 or more. A three factor structure was considered for evaluation as suggested in the previous step. The next step was to identify the factor structure matrix shown in Table 5. For a sample size of 119, factor loadings above 0.50 should be consider significant based on a 0.05 significance level, a power of $80 \%$ and a standard error assumed to be twice those from correlation coefficients (Hair et al, 2006). 
Table 5. Total Variance Explained

\begin{tabular}{|l|l|l|l|l|l|l|l|l|}
\hline \multirow{2}{*}{ Factor } & \multicolumn{4}{|l|}{ Initial Eigenvalues } & \multicolumn{2}{l|}{ Extraction Sums of Squared } & Rotation Sums of \\
\cline { 2 - 8 } & Total & \% of & Cumulative & Total & \% of & Cumulative & Total \\
\hline 1 & 3,285 & 41,058 & 41,058 & 2,842 & 35,520 & 35,520 & 2,176 \\
2 & 1,209 & 15,107 & 56,164 &, 817 & 10,207 & 45,728 & 2,002 \\
3 & 1,000 & 12,505 & 68,669 &, 567 & 7,089 & 52,816 & 1,870 \\
4 &, 778 & 9,731 & 78,400 & & & & \\
5 &, 605 & 7,559 & 85,960 & & & & \\
6 &, 436 & 5,454 & 91,414 & & & & \\
7 &, 388 & 4,852 & 96,265 & & & & & \\
8 &, 299 & 3,735 & 100,000 & & & & & \\
\hline
\end{tabular}

Extraction Method: Principal Axis Factoring

${ }^{\text {a }}$ When factors are correlated, sums of squared loadings cannot be added to obtain a total variance

In the factor structure matrix depicted in Table $6 \mathrm{a}$, a clear factor structure cannot be identified, considering that IA1 and IR2 show high loadings on two factors. This suggested the need to delete some of the factors and re-evaluate the structure. To decide which factor should be removed we observed at the communality level in Table 7a. The indicator which shows the lowest communality level is IT1 with 0,525. This can also be observed in the correlation matrix in Appendix G, in which this indicator did not show a significant correlation with any of the other indicators. Therefore, IT1 was removed from the model and again the factor structure matrix and commonality level were assessed. As a result, a three factor structure is proposed considering the clear structure shown in Table $6 \mathrm{~b}$, in which all the variables have high loadings only with a single factor and the minimum level of commonality of all the factors is 0,636 .

Table 6. Factor Structure Matrix: a) Initial model and b) final model

\begin{tabular}{|l|l|l|l|}
\hline \multirow{2}{*}{ a) } & \multicolumn{4}{|l|}{ Component } \\
\cline { 2 - 4 } & $\mathbf{1}$ & $\mathbf{2}$ & $\mathbf{3}$ \\
\hline IT3 & 0,86 & 0,125 & 0,156 \\
IT2 & 0,859 & 0,197 & 0,075 \\
ID1 & 0,182 & 0,863 & 0,038 \\
ID2 & 0,274 & 0,802 & 0,189 \\
IA1 & $-0,07$ & 0,614 & 0,536 \\
IR1 & 0,111 & 0,184 & 0,783 \\
IT1 & 0,149 & 0,06 & 0,707 \\
IR2 & 0,514 & 0,124 & 0,515 \\
\hline
\end{tabular}

\begin{tabular}{|l|l|l|l|}
\hline \multirow{2}{*}{ b) } & \multicolumn{4}{|l|}{ Component } \\
\cline { 2 - 4 } & $\mathbf{1}$ & $\mathbf{2}$ & $\mathbf{3}$ \\
\hline ID1 & 0,846 & 0,191 & 0,024 \\
ID2 & 0,802 & 0,28 & 0,161 \\
IA1 & 0,669 & $-0,069$ & 0,45 \\
IT2 & 0,216 & 0,872 & 0,021 \\
IT3 & 0,112 & 0,852 & 0,212 \\
IR1 & 0,189 & 0,067 & 0,892 \\
IR2 & 0,106 & 0,479 & 0,629 \\
\hline
\end{tabular}

Rotation Method: Varimax with Kaiser normalization. 
Table 7. Commonality using a principal component analysis: a) Initial model and b) final model

\begin{tabular}{|l|l|l|}
\hline a) & Initial & Extraction \\
\hline ID1 & 1,000 &, 780 \\
ID2 & 1,000 &, 753 \\
IA1 & 1,000 &, 669 \\
IT2 & 1,000 &, 782 \\
IT3 & 1,000 &, 780 \\
IR1 & 1,000 &, 659 \\
IR2 & 1,000 &, 545 \\
IT1 & 1,000 &, 525 \\
\hline
\end{tabular}

\begin{tabular}{|l|l|l|}
\hline b) & Initial & Extraction \\
\hline ID1 & 1,000 &, 753 \\
ID2 & 1,000 &, 748 \\
IA1 & 1,000 &, 655 \\
IT2 & 1,000 &, 807 \\
IT3 & 1,000 &, 784 \\
IR1 & 1,000 &, 836 \\
IR2 & 1,000 &, 636 \\
\hline
\end{tabular}

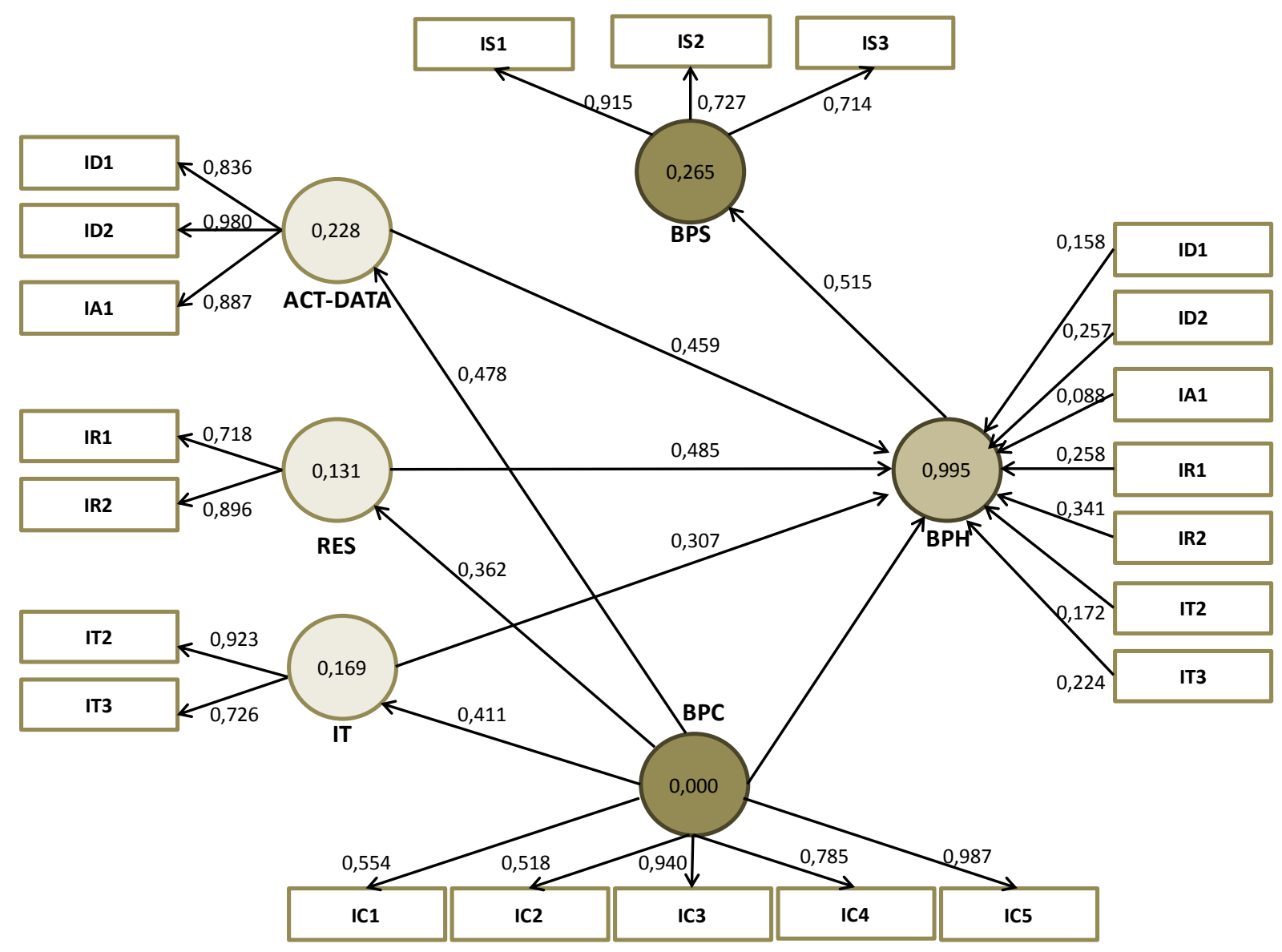

Figure 4. A repeated indicator Mode B PLS-SEM model for process harmonization (BPM)

\subsection{Final measurement model}

Partial Least Squares (PLS) was used to evaluate simultaneously the measurement model and the structural model relating the associated constructs. The repeated indicator Mode B PLS-SEM model used for our analysis is depicted in Figure 4. It shows how the indicators of each individual first-order 
construct (Activities/Data, Resources and IT) are repeated in the second-order construct (BPH). An exogenous construct, business process complexity (BPC), is linked to both first and second order constructs. And finally, a construct of business process standardization (BPS) is used as a final endogenous construct, considering that its indicators (IS1, IS2 and IS3) can be used as reflective indicators of $\mathrm{BPH}$.

The results gathered from the assessment of the reflective first-order construct are summarized in Appendix $H$ and Table 8. Appendix $H$ shows the loadings, $t$-values, average variance extracted (AVE) and composite reliability values for all the indicators and first-order constructs. The results of convergent validity are satisfactory, considering that all the loadings are above 0.50 , with a minimum value for the reflective indicators of $0.71($ IR1). All the reflectively measured first-order constructs (DATA, RES and IT) showed satisfactory values for convergent validity and reliability, with an AVE $>0.50$ and composite reliability above 0.70 . This suggests that the indicators account for a large portion of the variance of each latent construct. The R-squared of the measurement model of 0.995 shows that the formative higher order construct (BPH) is explained by its components (DATA, RES, IT). Looking at the t-values at the first-order construct level, all the weights are significant at a 0.05 level ( $\mathrm{t}>1.96)$.

Moreover, the variance inflator factor (VIF) used to test multi-collinearity among measures provided values between 1.20 and 1.96 which is below the threshold of 3. Table 8 shows the correlations between first-order construct and the square root of average extracted variance (AVE) highlighted in bold. It shows evidence of discriminant validity, because the squared root of AVE for all the firstorder constructs is greater than their correlation with other constructs in the model.

Table 8. Correlations of latent variables and evidence of discriminant validity

\begin{tabular}{|l|l|l|l|l|l|}
\hline Constructs & BPC & BPS & DATA & IT & RES \\
\hline BPC & $\mathbf{0 , 7 1 3 1}$ & & & & \\
\hline BPS & 0,5761 & $\mathbf{0 , 7 3 9 1}$ & & & \\
\hline DATA & 0,4686 & 0,3985 & $\mathbf{0 , 8 1 2 4}$ & & \\
\hline IT & 0,4170 & 0,3590 & 0,3699 & $\mathbf{0 , 9 1 3 2}$ & \\
\hline RES & 0,3547 & 0,4289 & 0,4575 & 0,4222 & $\mathbf{0 , 8 5 0 2}$ \\
\hline
\end{tabular}

\section{$5 \quad$ Results and discussion}

In line with the research goals, the analysis from the previous section yields a list of factors that influence the level of process harmonization of an organization (research goal 1) and a measurement model (research goal 2). Figure 5 summarizes the measurement model. The analysis has shown that 
the measurement model for process harmonization derived in this paper satisfies all the requirements for validity and reliability.

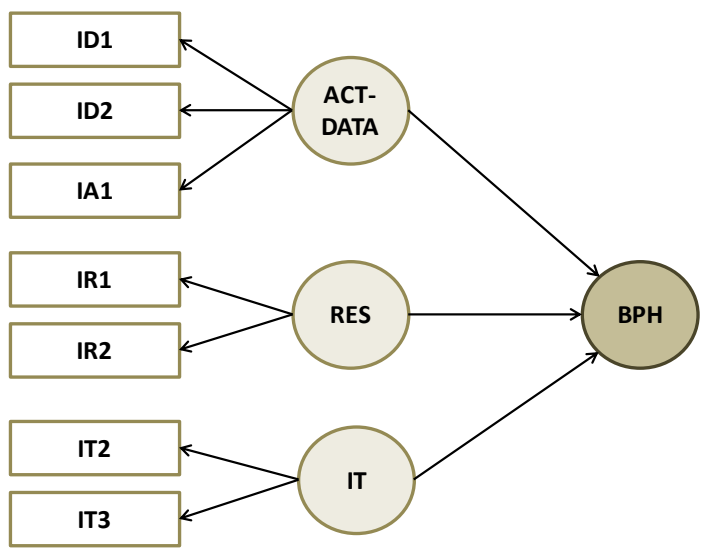

Figure 5. Revised hierarchical model (reflective first order and formative second order)

The measurement model clearly shows the factors that influence business process harmonization. Summarizing, they are:

- the technical design of the business process in terms of the activities that constitute the business process and in terms of the data items that are passed through the business process;

- the resources that are used in the execution of the business process; and

- the information technology that is used in the execution of the business process.

The factors are defined in a formative manner, such that they provide statistical evidence of the actions that can be taken in order to improve harmonization. For example, the variable ID1 indicates that business process harmonization can be improved by reducing the number of different documents that are used in different departments. Table 3 defines all the variables that can be improved to improve the harmonization of an organization's processes.

Just as interesting as the variables that are part of the model, are the variables that are not part of the model. In particular, the control-flow aspect of a business process is not part of the model and, therefore, not considered to substantially influence harmonization. This is especially interesting, because in business process management research much attention is paid to this aspect. There are two possible explanations for the fact that the control-flow aspect is missing from the measurement model. First, the model does consider that - in order to increase harmonization between processes - the activities in those processes must be aligned. It is possible that, when activities are aligned, the control-flow will automatically be aligned or not have a significant influence anymore. This is supported by previous research into similarity of processes (Dijkman et al. 2011), which shows that the similarity of processes is strongly determined by their activities; considering only activities is 
sufficient to accurately measure the similarity of processes, also considering control-flow does not provide much further accuracy. A second possible explanation is that the order in which activities in a business process are executed in practice often deviates from the modeled control-flow (Rozinat and van der Aalst 2008). Consequently, aligning the control-flows of the business processes may not have a sufficient effect on the behavior of employees.

\subsection{Harmonization and Standardization}

The correlation between process harmonization and process standardization is strong with a Pearson$\mathrm{R}$ of 0.58 . Consequently, hypothesis $\mathrm{H} 1$ holds: organizations that have a more harmonized processes, have a more standardized process.

The correlation between process harmonization and process standardization is expected and welldescribed in literature, as explained in Section 2. Indeed, in some papers the definitions of harmonization and standardization are even intertwined (e.g.: (Fernandez and Bhat 2010, p.368)). In this paper we choose to distinguish the two concepts, conform the definition of Richen and Steinhorst (2005) and we choose our operationalizations of the two concepts accordingly. Therefore, the correlation between the measurement model and process standardization is evidence of the validity of the measurement model. To an extent, the measurement model was derived from existing measurement models for standardization, as explained in Section 3. The relation between the concepts also follows from that by construction.

Regardless of the exact relation between process harmonization and process standardization, it is important to see that the operationalization of harmonization created in this paper is formative in the second order. Thus, it provides statistical evidence as to which factors can be influenced in order to improve the level of harmonization and therewith standardization of the processes in an organization.

\subsection{Harmonization and Complexity}

The correlation between process complexity and process harmonization is strong with a Pearson- $\mathrm{R}$ of 0.61. Consequently, hypothesis $\mathrm{H} 2$ holds: organizations that have less complex processes, have more harmonized processes.

The correlation between process complexity and process harmonization is primarily interesting from the perspective of the validity of the measurement model. As the relation between the complexity and harmonization is well-described in literature, the fact that we found it provides evidence of the validity of the measurement model. In addition to that, it shows that companies that want to 
harmonize (or standardize) their processes, should also work on reducing the complexity of their processes.

\section{Conclusions}

The first goal of this study was to determine the factors that influence the level of harmonization of business processes in an organization. Using a literature survey, interviews with domain experts and an on-line survey, these factors were determined to be the similarity of the resources that are used in the process, the similarity of the data items that are processed, including the similarity of the activities in which these data items are processed, and the similarity of the information technology that is used in the process.

The second goal of the paper was to build a measurement model for process harmonization, based on these factors. Using an on-line survey, a measurement model was constructed and evaluated, investigating both the internal and external consistency of the measurement model. The findings from the questionnaire provide evidence that the measurement model is indeed a valid and reliable tool for measuring process harmonization. The measurement model was constructed as a first-order reflective, second-order formative model, and as such also provides statistical evidence of the variables that can be adjusted in order to improve the harmonization of business processed. The conclusion is that, in order to improve the harmonization of processes, one must reduce the number of activities, data items, and resources that differ between the processes, as well as the number of different IT applications and the number of different suppliers of these applications.

A significant strength of our construction process is the multi-method approach followed, especially in the conceptualization step. It enriches the construct providing views from literature together with practice. The literature provided focus on the main aspects of the construct that were used for further operationalization. Using these initial set of aspects, practitioners defined measures from their practical experience. One limitation of this study is that we do not have a large number of indicators per aspect. This can lead to an under-specification of aspects that must be considered in the assessment of process harmonization. The measurement model cannot be evaluated containing only one indicator per aspect. Therefore, in our current study a maximum number of four aspects could be identified with the initial set of indicators generated. This is the case with the indicator IA1 which was theoretically defined as an indicator of Activities, and during the confirmatory phase was further combined with indicators of Data. It was not a surprise that it was combined with Data considering that the correlation between the harmonization of the steps followed in a process and the data input or 
output used, is stronger than the correlation of data with the number of resources used in the process or IT systems.

By conceptually developing and empirically validating the process harmonization construct, this study conveys an important message that effective harmonization initiatives requires an evaluation of the level of process harmonization achieved at different stages in the process to be able to link these measures with specific improvements in the organization. Eisenhardt (1989) states that "A conceptual model cannot be validated in terms of being true or not true, but it can be validated in terms of whether or not it is useful". In this case, our measurement model can be used by researchers and company executives to guide future research and practice. Researchers can use this systematically developed and validated measurement model as a starting point in the examination of the effects of process harmonization on business performance, or the link between organizational factors and the level of harmonization. In practice, this measurement model can assess the ratio of input and output of a single process harmonization program. This may serve to justify investments in these types of improvement programs. The conventional approach of simply investing in IT does not automatically lead to success of harmonization initiatives. One of the results of our research is that IT related measures only evaluate one aspect of the level of process harmonization.

While the development of a measurement model for process harmonization is an important result in itself, it is merely a necessary first step in doing research in the area of process harmonization. Now that the measurement model is defined, research questions with more practical relevance can be tackled, such as: what is the right level of process harmonization for my process or organization; and does process harmonization indeed lead to lower costs or higher performance. In another study, we already used the measurement model to answer the question what the best level of process harmonization is for an organization, considering properties of that organization (Romero, 2014).

\section{References}

Ang, Z, \& Massingham, P. (2007) National culture and the standardization versus adaptation of knowledge management. Journal of Knowledge Management, 11 (2), 5-21.

Armstrong, J. \& Overton, T. (1977) Estimating nonresponse bias in mail surveys. Journal of marketing research, 14, 396-402.

Becker, J.M., Klein, K. \& Wetzels M (2012) Hierarchical latent variable models in PLS-SEM: guidelines for using reflective-formative type models. Long Range Planning, 45, 359-394.

Beimborn, D., Gleisner, F., Joachim, N. \& Hackethal, A. (2009) The role of process standardization in achieving IT business value. In Proceedings of the 42nd Hawaii International Conference on System Sciences (Institute of Electrical and Electronics Engineers), 1-10, Waikoloa, Hawaii. 
Boersma, K. \& Kingma, S. (2005) Developing a cultural perspective on ERP. Business Process Management Journal, 11 (2), 123-136.

Bollen, KA. (1998) Structural equation models. John Wiley \& Sons, Ltd.

Buchta, D., Eul, M. \& Schulte-Croonenberg, H. (2010) Reducing costs-increasing the efficiency and effectiveness through IT. Strategic IT Management, 139-211.

Carmichael, D. (1997) IBM's journey towards a market-driven process-managed business model. Journal of Market-Focused Management, 2 (1), 99-103.

Chin, W.W. (1998) Commentary: Issues and opinion on structural equation modeling. MIS quarterly, vii-xvi.

Churchill, G.A. (1979) A paradigm for developing better measures of marketing constructs. Journal of Marketing Research, 16 (1), 64-73.

Collins, D. (2003) Pretesting survey instruments: an overview of cognitive methods. Quality of Life Research, 12(3), 229-238.

Conway, J.M. \& Huffcutt, A.I. (2003) A review and evaluation of exploratory factor analysis practices in organizational research. Organizational Research Methods, 6(2), 147-168.

Couper, M.P., Traugott, M.W. \& Lamias, M.J. (2001) Web survey design and administration. Public opinion quarterly, 65 (2), 230-253.

Crawford, S.D., Couper, M.P. \& Lamias, M.J. (2001) Web Surveys: Perception of burden. Social Science Computer Review, 19, 146-162.

Curran, T.A. \& Keller, G. (1999). SAP R/3 Business Blueprint - Business Engineering mit den R/3Referenzprozessen, Addison-Wesley, Bonn, Germany.

Dai, Q., Kau, R. \& Wang, B. (2011) The value of IT-enabled business process standardization from the real options perspective: Exploring the Grand Challenges for Next Generation E-Business. Lecture Notes in Business Information Processing, 52(1), 160-165.

Dess, G.G. \& Robinson, R.B. (1984) Measuring organizational performance in the absence of objective measures: the case of the privately held firm and conglomerate business unit. Strategic management journal, 5(3), 265-273.

Dijkman, R.M., Dumas, M., van Dongen, B.F., Käärik, R., Mendling, J. (2011) Similarity of Business Process Models: Metrics and Evaluation. Information Systems, 36(2), 498-516.

Dillman, D.A. (2011) Mail and internet surveys: The tailored design method--2007 Updated with new Internet, visual, and mixed-mode guide. Wiley.com

Ebert, C. (Ed.). (2005). Best Practices in Software Measurement: How to Use Metrics to Improve Project and Process Performance; 37 Tables. Springer.

Edwards, J. R. (2001). Multidimensional constructs in organizational behavior research: An integrative analytical framework. Organizational Research Methods, 4(2), 144-192.

Etter, J. F., \& Perneger, T. V. (1997). Analysis of non-response bias in a mailed health survey. Journal of clinical epidemiology, 50(10), 1123-1128.

Fernandez, J., \& Bhat, J. (2010). Addressing the Complexities of Global Process Harmonization. Handbook of Research on Complex Dynamic Process Management: Techniques for Adaptability in Turbulent Environments, IGI Global, 368-385. 
Fornell, C., \& Larcker, D. F. (1981). Evaluating structural equation models with unobservable variables and measurement error. Journal of marketing research, 39-50.

Foster, L. A., \& Herndon, B. T. (1997). Implementation of a Reengineered Procurement Process at Duke University, Using Technology and Work Process Design. Proceedings of the Information Profession and the Information Profession.

Girod, S.S \& Bellin, J. (2011) Revisiting the modern multinational enterprise theory: An emerging-market multi-national perspective. Research in Global Strategic Management, 15, 167-210.

Hair, J. F., Black, W. C., Babin, B. J., Anderson, R. E., \& Tatham, R. L. (2006). Multivariate Data Analysis Sixth Edition Pearson Education. New Jersey.

Hambrick, D. C., Geletkanycz, M. A., \& Fredrickson, J. W. (1993). Top executive commitment to the status quo: Some tests of its determinants. Strategic Management Journal, 14(6), 401-418.

Hammer, M. (1990) Reengineering work: Don’t automate, obliterate. Harvard Business Review, 104-112

Helfert, M. (2009) Challenges of business processes management in healthcare: Experience in the Irish healthcare sector. Business Process Management Journal 15(6), 937-952.

Hofreiter, B., Huemer, C., \& Winiwarter, W. (2005). Business collaboration models and their business contextdependent web choreography in BPSS. International Journal of Web Information Systems, 1(1), 33-42.

Hufgard, A. \& Gerhardt, E. (2011) Consolidating Business Processes as Exemplified in SAP ERP Systems. In S-BPM ONE-Learning by Doing-Doing by Learning, 155-171. Springer Berlin Heidelberg.

Jarvis, C. B., MacKenzie, S. B., \& Podsakoff, P. M. (2003). A critical review of construct indicators and measurement model misspecification in marketing and consumer research. Journal of consumer research, 30(2), 199-218.

Kobayashi, T., Onoda, S. \& Komoda, N. (2002) Workflow business template for application processes in administration department. Information Technology and Management, 3(1), 43-66.

Kubicek, H., Cimander, R. \& Scholl, H.J. (2011) Wants and Needs When Pursuing Interoperability. Organizational Interoperability in E-Government, 79-84.

Kumar, S. \& Harms, R. (2004) Improving business processes for increased operational efficiency: a case study. Journal of Manufacturing Technology Management 15(7), 662-674.

Küster, J., Gerth, C., Förster, A., Engels, G. (2008) Detecting and resolving process model differences in the absence of a change log. In: Proceedings of Business Process Management, Milan, Italy, Springer LNCS 5240, 244-260.

Law, K. S., Wong, C. S., \& Mobley, W. M. (1998). Toward a taxonomy of multidimensional constructs. Academy of Management Review, 23(4), 741-755.

Lee, J. Y., Lee, S., Kim, K., \& Kim, H. (2005). A process-centric engineering Web services framework. The International Journal of Advanced Manufacturing Technology, 26(9-10), 1173-1183.

van Liere, D. W., Hagdorn, L., Hoogeweegen, M. R., \& Vervest, P. H. (2004). Embedded coordination in a business network. Journal of Information Technology, 19(4), 261-269.

Löhmoller, J. (1989) Latent Variable Path Modeling with Partial Least Squares. Physica-Verlag, Heidelberg.

López-Ortega, O. \& Ramírez-Hernández, M. (2007) A formal framework to integrate express data models in an extended enterprise context. Journal of Intelligent Manufacturing, 18(3), 371-381. 
MacKenzie, S. B., Podsakoff, P. M., \& Podsakoff, N. P. (2011). Construct measurement and validation procedures in MIS and behavioral research: integrating new and existing techniques. MIS quarterly, 35(2), 293-334.

Martins, P. V., \& Silva, A. R. D. (2006). A case study applying process and project alignment methodology. Journal of the Brazilian Computer Society, 12(3), 65-82.

McLaren, T., Head, M., \& Yuan, Y. (2002). Supply chain collaboration alternatives: understanding the expected costs and benefits. Internet Research,12(4), 348-364..

Moffat, L. \& Archer, N. (2004) Knowledge management in production alliances. Information Systems and eBusiness Management, 2 (2), 241-267.

Mortensen, O. \& Lemoine, O. (2008) Integration between manufacturers and third party logistics providers? International Journal of Operations \& Production Management, 28 (4), 331-359.

Münstermann, B., Eckhardt, A. \& Weitzel, T. (2009) Join the standard forces examining the combined impact of process and data standards on business process performance. In Proceedings of the 42nd Hawaii International Conference on System Sciences (Institute of Electrical and Electronics Engineers), 1-10, Waikoloa, Hawaii.

Münstermann, B., Eckhardt, A. \& Weitzel, T. (2010) The performance impact of business process standardization: An empirical evaluation of the recruitment process, Business Process Management Journal, $16(1), 29-56$.

Münstermann, B., Von Stetten, A., Laumer, S. \& Eckhardt, A. (2010) The performance impact of business process standardization: HR case study insights. Management Research Review, 33(9), 924-939.

Norta, A. \& Eshuis, R. (2010) Specification and verification of harmonized business process collaborations. Information Systems Frontier, 12, 457-479.

Perego, A. \& Salgaro, A. (2010) Assessing the benefits of B2B trade cycle integration: a model in the home appliances industry. Benchmarking: An International Journal, 17 (4), 616-630.

Riempp, G., \& Gieffers-Ankel, S. (2007) Application portfolio management: a decision-oriented view of enterprise architecture. Information Systems and e-Business Management, 5(4), 359-378.

Ringle, C., Sarstedt, M. \& Straub, D. (2012) A critical look at the use of PLS-SEM in MIS quarterly. Management Information Systems (MIS) Quarterly, 36(1), iii-xiv.

Rohloff, M. (2011) Advances in business process management implementation based on a maturity assessment and best practice exchange. Information Systems E-Business Management, 9, 383-403.

Romero, H. (2014) The Role of Contextual Factors in Process Harmonization. Ph.D. Thesis, Eindhoven University of Technology, Eindhoven, The Netherlands.

Rosenkranz, C., Seidel, S., Mendling, J., Schaefermeyer, M., \& Recker, J. (2010, January). Towards a framework for business process standardization. In: Business process management workshops (pp. 53-63). Springer, Berlin-Heidelberg.

Ross, J., Weill, P. \& Robertson, D. (2006) Enterprise architecture as strategy. Harvard Business School Press, Boston, MA, USA.

Rozinat, A. \& van der Aalst, W..M.P. (2008) Conformance Checking of Processes Based on Monitoring Real Behavior. Information Systems, 33(1), 64-95. 
Schäfermeyer, M., Grgecic, D. \& Rosenkranz, C. (2010) Factors influencing business process standardization: A multiple case study. In Proceedings System Sciences (HICSS), 43rd Hawaii International Conference, IEEE, 1-10.

Schäfermeyer, M., Rosenkranz, C., \& Holten, R. (2012) The Impact of Business Process Complexity on Business Process Standardization: An Empirical Study. Business \& Information Systems Engineering 4(5), 261-270.

Schmidt, A., Otto, B. \& Österle, H. (2010) Integrating information systems: case studies on current challenges. Electronic Markets, 20 (2), 161-174.

Sedera, D. \& Dey, S. (2007) Everyone is Different! Exploring the Issues and Problems with ERP Enabled Shared Service Initiatives. In: Proceedings of AMCIS, Association for Information Systems.

Shang, S. \& Seddon, P.B. (2007) Managing process deficiencies with enterprise systems. Business Process Management Journal, 13(3), 405-416.

Sheikh, K. \& Mattingly, S. (1981) Investigating non-response bias in mail surveys. Journal of epidemiology and community health, 35(4), 293-296.

Shin, B. \& Kim, G. (2011) Investigating the reliability of second-order formative measurement in information systems research. European Journal of Information Systems, 20(5), 608-623.

Sorenson, O. \& Sorenson, J.B. (2001) Finding the right mix: Franchising, organizational learning, and chain performance. Strategic Management Journal, 22, 713-724.

Strauss, A. \& Corbin, J. (1998) Basics of qualitative research: Techniques and procedures for developing grounded theory. Second ed. SAGE Publications, Thousand Oaks, California.

Tourangeau, R., Rips, L.J. \& Rasinski, K.A. (2000) The psychology of survey response. Cambridge: Cambridge University Press.

Tregear, R. (2010) Business process standardization. Handbook on Business Process Management, 2, 307-327.

Vanwersch, R. J. B., Shahzad, K., Vanhaecht, K., Grefen, P. W. P. J., Pintelon, L. M., Mendling, J., ... \& Reijers, H. A. (2011). Methodological support for business process redesign in health care: a literature review protocol. International Journal of Care Pathways, 15(4), 119-126.

Webster, J. \& Watson, R.T. (2002) Analyzing the Past to Prepare for the Future: Writing a Literature Review. Management Information Systems (MIS) Quarterly, 26 (2), 13-23.

Wilson, B. \& Henseler, J. (2007) Modeling reflective higher-order constructs using three approaches with PLS path modeling: a Monte Carlo comparison. In Australian and New Zealand Marketing Academy Conference, 791-800.

Wüllenweber, K., Koenig, W., Beimborn, D. \& Weitzel, T. (2008) The impact of process standardization on business process outsourcing success. Information Systems Frontiers, 10 (2), 211-224.

Zhao, F. (2004) Management of information technology and business process reengineering: a case study. Industrial Management \& Data Systems, 104 (8), 674-680. 


\section{Appendix A}

\begin{tabular}{|c|c|c|c|c|}
\hline Keywords & $\begin{array}{l}\text { Google } \\
\text { Scholar }\end{array}$ & ABI/INFORMS & EMERALD & Springer \\
\hline "business process harmonization" & 10 & 2 & 0 & 2 \\
\hline "harmonization of business processes" & 31 & 0 & 1 & 7 \\
\hline "harmonization of processes" & 58 & 1 & 6 & 9 \\
\hline "process harmonization" & 172 & 10 & 8 & 25 \\
\hline "business processes standardization" & 33 & 13 & 2 & 2 \\
\hline "process standardization" AND "business processes" & & 21 & 31 & 22 \\
\hline "standardization of business processes" & & 12 & 0 & 20 \\
\hline "standard process" AND "business processes" & & 29 & 14 & 30 \\
\hline "harmonize" AND "business processes" & & 11 & 0 & 32 \\
\hline "standardize" AND "business processes" & & 12 & 4 & 92 \\
\hline "process variants" & & 33 & 17 & 45 \\
\hline harmonization AND "business process" & & 16 & 5 & 3 \\
\hline "Franchising" AND "standardization" & & 3 & 11 & 1 \\
\hline (mergers OR adquisitions) AND standardization & & 36 & 16 & 3 \\
\hline
\end{tabular}

Table A.1. Number of papers found per combination of keyword/literature source

\section{General criteria}

1. The report is written in English

2. Data from one study did not overlap data from another study

\section{Relevance inclusion criteria}

1. The article provides a definition of harmonization in the context of business processes.

2. The article provides a description of a harmonization process, including different steps that provide enough information to derive a definition of the concept.

3. The study describes a methodology to conduct harmonization projects.

4. The study presents an empirical application of process harmonization.

5. The study describes a relationship (direct effect, moderator, and mediator) between contextual factors and process harmonization.

6. The study describes a relationship (direct effect, moderator, and mediator) between process harmonization and business performance.

\section{Quality inclusion criteria}

1. The article is a published journal or conference paper.

2. The method used to derive the results is explained in the article

Table A.2. Inclusion criteria used for selecting papers 


\section{Appendix B \\ Survey instrument}

An online survey was conducted to generate indicators of process harmonization. The survey questionnaire is included bellow, including its access link. This section presents a description of the process followed for the survey development and data collection, and a justification of decisions made in the process.

\section{A1. Questionnaire}

This survey can be reached using the following link:

https://docs.google.com/spreadsheet/viewform?fromEmail=true\&formkey=dEJ2N183S0MzZkFKc01 hNXQ2cnpzM0E6MQ

\section{Survey on Business Process Harmonization}

The purpose of this survey is to identify indicators for measuring the level of harmonization of business processes in an organization. Business process harmonization is important for practitioners and researchers in the BPM community, because it is critical for a successful implementation of IT solutions and process improvement.

We appreciate your collaboration in this research answering a questionnaire of 14 questions that will take approximately 5 to 10 minutes of your time. It will help us to conduct further empirical research to investigate the appropriate level of harmonization for organizations in different contexts (i.e. multinational versus domestic organizations).

We would like you to share your opinions with us, and the information that you provide and your participation will be held as confidential. Please contact us with any questions or concerns about this survey at h.1.romero@tue.nl

Thank you for your participation in this survey!!

\section{Question \#1}

Have you participated in a project for process standardization or process harmonization in a company?

- Yes

$\circ$ No

\section{Question \#2}

\section{What was your role in this project?}
- Project manager
○ Manager
- Process architect
- Business analyst
- Consultant 


\section{Question \#3}

Can you describe specific activities that were performed as part of this project and the processes involved?

\section{Question \#4}

\section{How long did you work on this project?}

Less than 1 years

1 to 3 years

More than 3 years

\section{Question \#5}

How would you score your knowledge about process harmonization?

$\begin{array}{llllllllll}1 & 2 & 3 & 4 & 5 & 6 & 7 & 8 & 9 & 10\end{array}$

000000000

\section{Question \#6}

\section{What is process harmonization according to you?}

\section{Illustrative example of process harmonization}

In this survey we assume that process harmonization refers to how uniform and comparable two processes are. For example, the process of admitting a student to a university is fairly similar for different universities in the Netherlands, because it is regulated by the government. Therefore, we say that the level of harmonization for these admissions processes is high.

In contrast, the process of hiring new personnel probably differs for different Dutch organizations, because different organizations execute it differently, depending on their size, whether they have it outsourced. Therefore, we say that the level of harmonization for these hiring processes is low.

Use this assumption to answer the following questions. Press continue to proceed.

\section{Back Continue}

\section{Question \#7}

To what extent do you agree with the following statements? 
If processes are more harmonized...

$\begin{array}{cccc}\text { Completely } & \text { Mostly } & \text { Neither } & \text { Completely } \\ \text { disagree } & \text { disagree } & \text { agree/disagree } & \text { Mostly agree } \\ \text { agree }\end{array}$

...the execution of the business process is strongly standardized.
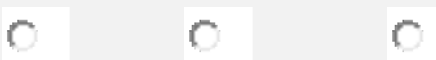

C

C

...they can easily be learned

via documentation and trainings.

...the process-cycle is well regulated during the execution of the business

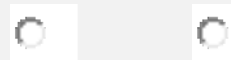

process.

\section{Question \#8}

To what extent do you agree with the following statements?

If processes are less harmonized...

$\begin{array}{ccccc}\text { Completely } & \text { Mostly } & \text { Neither } & \text { Completely } \\ \text { disagree } & \text { disagree } & \text { agree/disagree } & \text { Mostly agree } & \text { agree }\end{array}$

...the employees

executing the business process need to be able

to flexible adjust themselves to the

differing process sequences. 


\begin{tabular}{|c|c|}
\hline $\begin{array}{l}\text { ompletely } \\
\text { disagree }\end{array}$ & $\begin{array}{l}\text { Mostly } \\
\text { disagree }\end{array}$ \\
\hline
\end{tabular}

...the set of inputs necessary for process execution differ often.

...the business process

is characterized by uncertainty.

...the business process is very complex.

\section{Question \#9}

If you want to evaluate the level of harmonization, which aspects are important to consider?

\begin{tabular}{|c|c|c|c|}
\hline Not at all & Not very & Neutral & Somewhat \\
\hline
\end{tabular}

$\begin{array}{r}\text { Activities (including the } \\
\text { order in which they are } \\
\text { performed) }\end{array}$
\begin{tabular}{rl|l|l|} 
Information that is used \\
in the processes
\end{tabular}
Resources that perform
the processes




\begin{tabular}{|c|c|c|c|}
\hline $\begin{array}{l}\text { Not at all } \\
\text { important }\end{array}$ & $\begin{array}{l}\text { Not very } \\
\text { important }\end{array}$ & Neutral & $\begin{array}{l}\text { Somewhat } \\
\text { important }\end{array}$ \\
\hline
\end{tabular}

Software applications

that are used in the

process

C $\quad$ r

C

C $\quad 0$

Are there any other aspects that must be considered?

\section{Question \#10}

To what extent do you agree with the following statements?

The level of harmonization of "information" can be quantified using the following measures:

$\begin{array}{ccccc}\text { Completely } & \text { Mostly } & \text { Neither } & \text { Completely } \\ \text { disagree } & \text { disagree } & \text { agree/disagree } & \text { Mostly agree } & \text { agree }\end{array}$

The number of

different documents

used as input for the

same process

The number of

different output reports

What other measures can be used to quantify the level of harmonization of "information"?

\section{Question \#11}

To what extent do you agree with the following statements?

The level of harmonization of "activities" can be quantified using the following measure: 


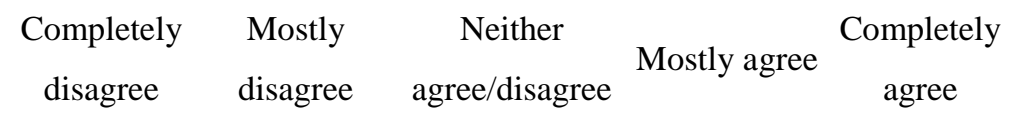

The percentage of common activities in the process

What other measures can be used to quantify the level of harmonization of "activities"(including the order in which they are performed)?

\section{Question \#12}

To what extent do you agree with the following statements?

The level of harmonization of "software applications" can be quantified using the following measures:

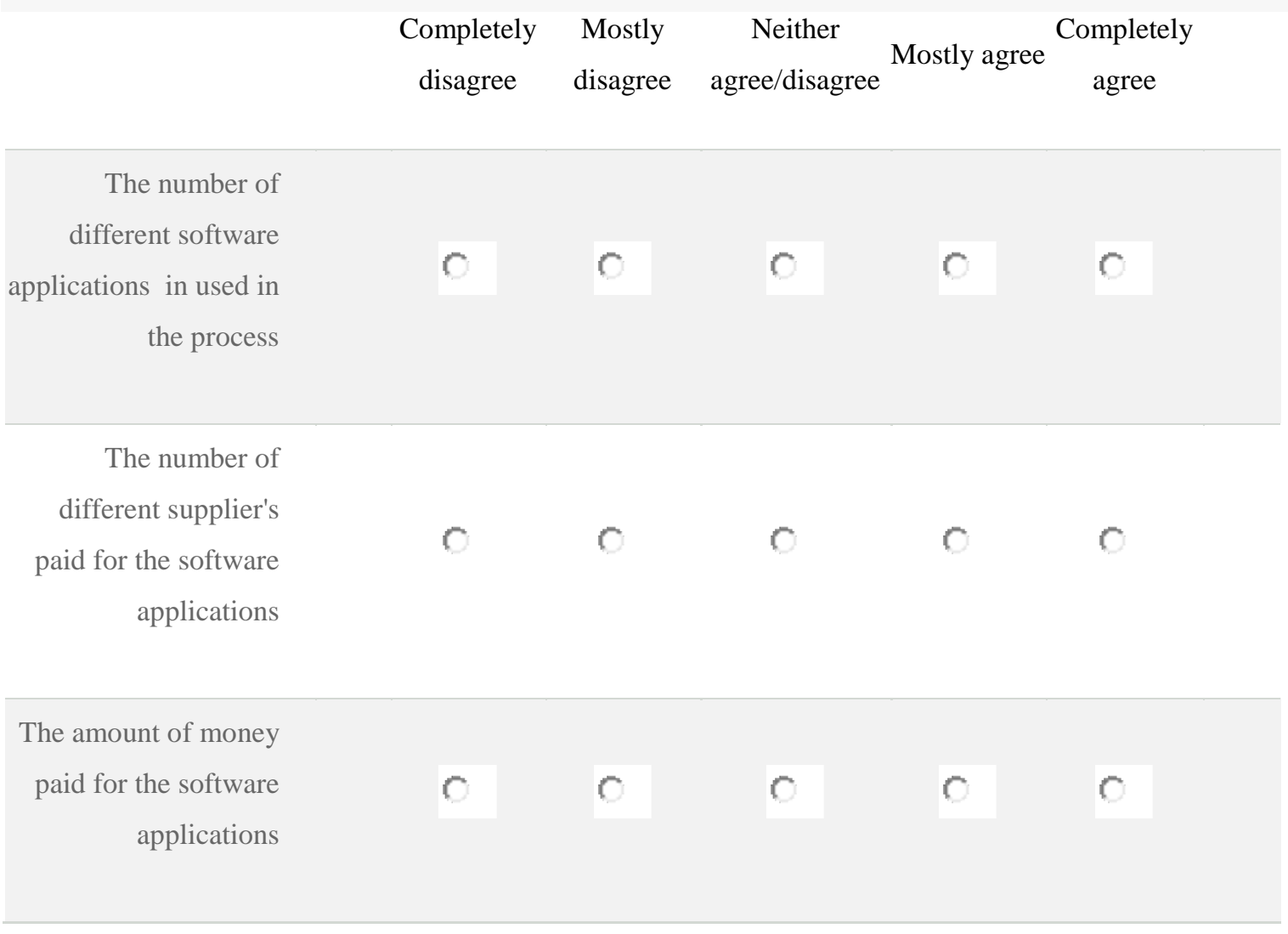

What other measures can be used to quantify the level of harmonization of "software applications"? 


\section{Question \#13}

To what extent do you agree with the following statements?

The level of harmonization of "resources" that perform the processes can be quantified using the following measures:

$\begin{array}{cccc}\text { Completely } & \text { Mostly } & \text { Neither } & \text { Completely } \\ \text { disagree } & \text { disagree } & \text { agree/disagree } & \text { Mostly agree } \\ \text { agree }\end{array}$

The percentage of common roles in the process.
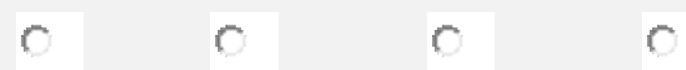

process.

The number of

different roles

executing the same

activity.

What other measures can be used to quantify the level of harmonization of "resources"?

\section{Question \#14}

In the last question of this survey we want to know, if you engage in a harmonization project and after the project your processes are more harmonized. Which elements (of your processes or your organization as a whole) do you expect to have changed? For example, the number of common activities increases.

\section{Thank you for participating in this survey!}

Please indicate your e-mail address, if you would like to receive a summary report of the findings of this research: 


\section{Appendix C}

Description of constructs and measures used in the survey

\begin{tabular}{|l|l|l|}
\hline \multicolumn{1}{|c|}{ Construct } & \multicolumn{1}{|c|}{ Item } & \\
\hline BPS & BPS1 & The execution of the business process is strongly standardized. \\
\cline { 2 - 4 } & BPS2 & We have documented all actions of the business process to a great extent. \\
\cline { 2 - 4 } & BPS3 & During the execution of the process we follow a well-regulated process cycle. \\
\hline BPC & BPC1 & The employees executing the business process need to be able to flexible \\
& adjust themselves to the differing process sequences. \\
\cline { 2 - 4 } & BPC2 & The set of inputs necessary for process execution differ often. \\
\cline { 2 - 4 } & BPC3 & The business process is characterized by uncertainty. \\
\cline { 2 - 4 } & BPC4 & The business process is very complex. \\
\hline & BPC5 & A lot of information is needed to execute the business process. \\
\hline
\end{tabular}




\section{Appendix D \\ Questionnaire for pre-testing the survey instrument}

\section{Survey questions}

For questions $\# 1,2,3$ and 4

For question \#5

\section{Pre-test questions}

1. When we asked questions about your experience in harmonization projects: 1.1. Did you have a particular time period in mind? (i.e. in the last five years) 1.2. How well do you remember this information?

2. When we asked to evaluate your knowledge about process harmonization, how did you estimate your answer?

For question \#6 3. What do the terms 'process harmonization' and 'process standardization' mean to you?

For question \#7 4. What do the terms 'level of similarity' and 'level of compatibility' mean to you?

5. How sure of your answer are you?

6. Were you able to find your first answer to the question from the response option shown?

For question \#8 7. What does the term 'standard' mean to you?

and 9 . How sure of your answer are you?

9. Were you able to find your first answer to the question from the response option shown?

For question 10. How did you get your answer?

\#10 11. How sure of your answer are you?

12. How did you feel about answering this question?

General 13. Do you have comments about the wording or how some specific question is described? Please provide any additional comments to improve this survey instrument. 


\section{Appendix E}

Group Statistics of responses (ID1, ID2, IA1, IT1,IT2 and IT3) for 1 early respondents and 2 late respondents

\begin{tabular}{|c|c|c|c|c|c|c|c|}
\hline \multirow{3}{*}{ RESF } & & & \multirow{3}{*}{ Statistic } & \multicolumn{4}{|c|}{ Bootstrap $^{a}$} \\
\hline & & & & \multirow{2}{*}{ Bias } & \multirow{2}{*}{ Std. Error } & \multicolumn{2}{|c|}{ 95\% Confidence } \\
\hline & & & & & & Lower & Upper \\
\hline \multirow[t]{8}{*}{ ID1 } & 1 & $\mathrm{~N}$ & 100 & & & & \\
\hline & & Mean & 3,22 & ,00 &, 12 & 2,98 & 3,46 \\
\hline & & Std. Deviation & 1,168 &,- 011 & ,095 & ,954 & 1,341 \\
\hline & & Std. Error Mean & 117 & & & & \\
\hline & 2 & $\mathrm{~N}$ & 19 & & & & \\
\hline & & Mean & 2,79 & , 00 & ,23 & 2,33 & 3,27 \\
\hline & & Std. Deviation & 1,032 &,- 030 & 147 & ,717 & 1,286 \\
\hline & & Std. Error Mean & 237 & & & & \\
\hline \multirow[t]{8}{*}{ ID2 } & 1 & $\mathrm{~N}$ & 100 & & & & \\
\hline & & Mean & 3,42 & ,00 & ,11 & 3,19 & 3,63 \\
\hline & & Std. Deviation & 1,093 &,- 012 & ,084 & ,905 & 1,242 \\
\hline & & Std. Error Mean & 109 & & & & \\
\hline & 2 & $\mathrm{~N}$ & 19 & & & & \\
\hline & & Mean & 3,58 &, 01 & ,24 & 3,10 & 4,05 \\
\hline & & Std. Deviation & 1,017 &,- 040 & ,192 & ,624 & 1,339 \\
\hline & & Std. Error Mean & ,233 & & & & \\
\hline \multirow[t]{8}{*}{ IA1 } & 1 & $\mathrm{~N}$ & 100 & & & & \\
\hline & & Mean & 3,50 & ,00 &, 12 & 3,26 & 3,72 \\
\hline & & Std. Deviation & 1,150 &,- 011 & 095 & 954 & 1,316 \\
\hline & & Std. Error Mean &, 115 & & & & \\
\hline & 2 & $\mathrm{~N}$ & 19 & & & & \\
\hline & & Mean & 3,58 & ,02 & ,22 & 3,12 & 4,05 \\
\hline & & Std. Deviation & 1,017 &,- 037 & ,127 & ,712 & 1,215 \\
\hline & & Std. Error Mean & 233 & & & & \\
\hline \multirow[t]{8}{*}{ IT1 } & 1 & $\mathrm{~N}$ & 100 & & & & \\
\hline & & Mean & 3,53 &, 00 & ,09 & 3,34 & 3,70 \\
\hline & & Std. Deviation & ,881 &,- 011 & , 091 & 699 & 1,051 \\
\hline & & Std. Error Mean & ,088 & & & & \\
\hline & 2 & $\mathrm{~N}$ & 19 & & & & \\
\hline & & Mean & 3,79 & ,01 & ,18 & 3,42 & 4,13 \\
\hline & & Std. Deviation & ,787 &,- 041 & ,165 & ,394 & 1,044 \\
\hline & & Std. Error Mean & ,181 & & & & \\
\hline
\end{tabular}

a. Unless otherwise noted, bootstrap results are based on 1000 bootstrap samples 
Continued from previous page - Group Statistics of responses (ID1, ID2, IA1, IT1,IT2 and IT3) for 1 early respondents and 2 late respondents

\begin{tabular}{|c|c|c|c|c|c|c|c|}
\hline \multirow{3}{*}{ RESP } & & & \multirow{3}{*}{ Statistic } & \multicolumn{4}{|c|}{ Bootstrap $^{a}$} \\
\hline & & & & \multirow{2}{*}{ Bias } & \multirow{2}{*}{ Std. Error } & \multicolumn{2}{|c|}{ 95\% Confidence } \\
\hline & & & & & & Lower & Upper \\
\hline \multirow[t]{8}{*}{ IT2 } & 1 & $\mathrm{~N}$ & 100 & & & & \\
\hline & & Mean & 2,34 & ,00 & , 10 & 2,13 & 2,54 \\
\hline & & Std. Deviation & 1,017 &,- 010 & ,064 & ,879 & 1,142 \\
\hline & & Std. Error Mean & , 102 & & & & \\
\hline & 2 & $\mathrm{~N}$ & 19 & & & & \\
\hline & & Mean & 2,21 & ,01 & ,19 & 1,85 & 2,62 \\
\hline & & Std. Deviation & 855 &,- 040 & 189 & 342 & 1,123 \\
\hline & & Std. Error Mean & , 196 & & & & \\
\hline \multirow[t]{8}{*}{ IT3 } & 1 & $\mathrm{~N}$ & 100 & & & & \\
\hline & & Mean & 2,06 & , 00 & ,09 & 1,88 & 2,23 \\
\hline & & Std. Deviation & ,862 &,- 008 & ,060 & ,739 & 971 \\
\hline & & Std. Error Mean & ,086 & & & & \\
\hline & 2 & $\mathrm{~N}$ & 19 & & & & \\
\hline & & Mean & 2,00 & ,01 & ,11 & 1,78 & 2,21 \\
\hline & & Std. Deviation & ,471 &,- 029 & ,115 & 224 & 649 \\
\hline & & Std. Error Mean & ,108 & & & & \\
\hline \multirow[t]{8}{*}{ IR1 } & 1 & $\mathrm{~N}$ & 100 & & & & \\
\hline & & Mean & 3,74 & , 00 & , 10 & 3,54 & 3,92 \\
\hline & & Std. Deviation & ,939 &,- 022 & ,122 & 677 & 1,155 \\
\hline & & Std. Error Mean & ,094 & & & & \\
\hline & 2 & $\mathrm{~N}$ & 19 & & & & \\
\hline & & Mean & 3,79 & ,02 & , 16 & 3,47 & 4,12 \\
\hline & & Std. Deviation & ,713 &,- 038 & 141 & 403 & 943 \\
\hline & & Std. Error Mean & ,164 & & & & \\
\hline \multirow[t]{8}{*}{ IR2 } & 1 & $\mathrm{~N}$ & 100 & & & & \\
\hline & & Mean & 3,37 & , 00 & , 10 & 3,16 & 3,57 \\
\hline & & Std. Deviation & ,991 &,- 011 & , 080 & ,838 & 1,146 \\
\hline & & Std. Error Mean & ,099 & & & & \\
\hline & 2 & $\mathrm{~N}$ & 19 & & & & \\
\hline & & Mean & 3,16 & ,01 & 23 & 2,72 & 3,58 \\
\hline & & Std. Deviation & 1,015 &,- 038 & 094 & 800 & 1,166 \\
\hline & & Std. Error Mean & ,233 & & & & \\
\hline
\end{tabular}

a. Unless otherwise noted, bootstrap results are based on 1000 bootstrap samples 


\section{Appendix F}

Results of Independent sample T-test to compare the responses of (1) early and (2) late respondents, with respect to all the indicators evaluated during the survey

\begin{tabular}{|c|c|c|c|c|c|c|c|c|c|c|}
\hline & \multicolumn{2}{|c|}{ Levene's Test for Equality of } & \multicolumn{7}{|c|}{ t-test for Equality of Means } \\
\hline & & \multirow{2}{*}{$\mathrm{F}$} & \multirow[t]{2}{*}{ Sig. } & \multirow{2}{*}{$\mathrm{t}$} & \multirow{2}{*}{$\mathrm{df}$} & \multirow{2}{*}{$\begin{array}{l}\text { Sig. 2- } \\
\text { tailed }\end{array}$} & \multirow{2}{*}{$\begin{array}{c}\text { Mean } \\
\text { Difference }\end{array}$} & \multirow{2}{*}{$\begin{array}{l}\text { Std. Error } \\
\text { Difference }\end{array}$} & \multicolumn{2}{|c|}{ 95\% Confidence Interval of the } \\
\hline & & & & & & & & & Lower & Upper \\
\hline ID1 & Equal variances assumed & 240 & 625 & 1,498 & 117 & ,137 & 431 & 287 &,- 139 & 1,000 \\
\hline & Equal variances not & & & 1,631 & 27,546 &, 114 & ,431 & ,264 &,- 111 & ,972 \\
\hline ID2 & Equal variances assumed & ,480 & ,490 &,- 587 & 117 &, 558 &,- 159 &, 271 &,- 695 & ,377 \\
\hline & Equal variances not & & & -617 & 26,535 &, 543 &,- 159 &, 258 &,- 688 &, 370 \\
\hline IA 1 & Equal variances assumed &, 190 & ,663 &,- 279 & 117 &, 781 &,- 079 & ,283 &,- 639 & , 482 \\
\hline & Equal variances not & & &,- 303 & 27,511 &, 764 &,- 079 &, 260 &,- 612 & ,455 \\
\hline IT1 & Equal variances assumed & 1,443 & ,232 & $-1,195$ & 117 &, 234 &,- 259 &, 217 &,- 689 &, 171 \\
\hline & Equal variances not & & & $-1,291$ & 27,311 & ,208 &,- 259 & ,201 &,- 672 & ,153 \\
\hline IT2 & Equal variances assumed & 3,673 &, 058 &, 520 & 117 & 604 &, 129 &, 249 &,- 363 & ,622 \\
\hline & Equal variances not & & &, 586 & 28,608 &, 562 &, 129 &, 221 &,- 323 &, 582 \\
\hline IT3 & Equal variances assumed & 7,530 & 007 & 294 & 117 &, 769 &, 060 & ,204 &,- 344 & ,464 \\
\hline & Equal variances not & & &, 434 & 44,876 & ,667 &, 060 &, 138 &,- 219 &, 339 \\
\hline IR1 & Equal variances assumed &, 394 &, 531 &,- 218 & 117 & 828 &,- 049 &, 227 &,- 499 &, 400 \\
\hline & Equal variances not & & &,- 262 & 31,183 &, 795 &,- 049 & ,189 &,- 434 & ,335 \\
\hline IR2 & Equal variances assumed & ,425 &, 516 &, 852 & 117 & ,396 &, 212 &, 249 &,- 281 &, 705 \\
\hline & Equal variances not & & & 838 & 24,975 &, 410 &, 212 &, 253 &,- 309 & ,733 \\
\hline
\end{tabular}


Appendix G

\begin{tabular}{|c|c|c|c|c|c|c|c|c|c|}
\hline & & ID1 & ID2 & IA1 & IT1 & IT2 & IT3 & IR1 & IR2 \\
\hline \multirow[t]{2}{*}{ ID1 } & Pearson Correlation & 1 & 0,605 & 0,409 & ,166 & 0,276 & 0,263 & 0,232 & 0,28 \\
\hline & Sig. (1-tailed) & &, 000 & ,000 & ,035 & ,001 & ,002 & ,006 & ,001 \\
\hline \multirow[t]{2}{*}{ ID2 } & Pearson Correlation & 0,605 & 1 & 0,466 & 0,25 & 0,381 & 0,323 & 0,325 & 0,349 \\
\hline & Sig. (1-tailed) & ,000 & &, 000 & ,003 & ,000 & ,000 & ,000 &, 000 \\
\hline \multirow[t]{2}{*}{ IA1 } & Pearson Correlation & 0,409 & 0,466 & 1 & 0,339 & 0,194 &, 175 & 0,428 & 0,223 \\
\hline & Sig. (1-tailed) & ,000 & ,000 & & ,000 & 017 & ,028 & ,000 & ,007 \\
\hline \multirow[t]{2}{*}{ IT1 } & Pearson Correlation & ,166 & 0,25 & 0,339 & 1 & 0,268 & 0,199 & 0,304 & 0,276 \\
\hline & Sig. (1-tailed) &, 035 &, 003 &, 000 & & ,002 &, 015 &, 000 &, 001 \\
\hline \multirow[t]{2}{*}{ IT2 } & Pearson Correlation & 0,276 & 0,381 & 0,194 & 0,268 & 1 & 0,654 &, 157 & 0,372 \\
\hline & Sig. (1-tailed) &, 001 &, 000 &, 017 &, 002 & &, 000 &, 044 &, 000 \\
\hline \multirow[t]{2}{*}{ IT3 } & Pearson Correlation & 0,263 & 0,323 &, 175 & 0,199 & 0,654 & 1 & 0,295 & 0,41 \\
\hline & Sig. (1-tailed) &, 002 &, 000 & ,028 &, 015 & ,000 & &, 001 &, 000 \\
\hline \multirow[t]{2}{*}{ IR1 } & Pearson Correlation & 0,232 & 0,325 & 0,428 & 0,304 & ,157 & 0,295 & 1 & 0,435 \\
\hline & Sig. (1-tailed) & ,006 &, 000 & ,000 &, 000 &, 044 &, 001 & &, 000 \\
\hline \multirow[t]{2}{*}{ IR2 } & Pearson Correlation & 0,28 & 0,349 & 0,223 & 0,276 & 0,372 & 0,41 & 0,435 & 1 \\
\hline & Sig. (1-tailed) & ,001 &, 000 &, 007 & ,001 &, 000 &, 000 &, 000 & \\
\hline
\end{tabular}

**. Correlation is significant at the 0.01 level (1-tailed).

*. Correlation is significant at the 0.05 level (1-tailed). 


\section{Appendix H}

Results of the assessment of reflective first-order construct: evidence of convergent validity

\begin{tabular}{|c|c|c|c|c|c|c|}
\hline \multicolumn{2}{|c|}{ Constructs } & \multirow[t]{2}{*}{ Loadings } & \multicolumn{2}{|r|}{ t-value } & \multirow{2}{*}{\begin{aligned} \multicolumn{1}{l}{$A V E$} \\
$\mathbf{0 . 8 5 2 9}\end{aligned}$} & \multirow[t]{2}{*}{ Composite } \\
\hline Data & & & 2.3466 & 0.6600 & & \\
\hline IA1 & The percentage of common activities in the process. & 0,7366 & & 11.2811 & & \\
\hline ID1 & The number of different documents used as input for the same process. & 0,8485 & & 43.6912 & & \\
\hline ID2 & The number of different output reports. & 0,8469 & & 22.4686 & & \\
\hline \multicolumn{2}{|c|}{ Resources } & & 2.4602 & 0.7228 & 0.8389 & \\
\hline IR1 & The percentage of common roles in the process. & 0,8165 & & 9.4556 & & \\
\hline IR2 & The number of different roles executing the same activity. & 0,8826 & & 28.7927 & & \\
\hline IT & & & 2.2413 & 0.8339 & 0.9094 & \\
\hline IT2 & The number of different supplier's paid for the software applications. & 0,9066 & & 29.8478 & & \\
\hline IT3 & The amount of money paid for the software applications. & 0,9197 & & 69.6419 & & \\
\hline \multicolumn{2}{|c|}{ Business Process Standardization (BPS) } & & 6.1067 & 0.5462 & 0.7801 & \\
\hline IS1 & The execution of the business process is strongly standardized. & 0,8048 & & 13,8649 & & \\
\hline IS2 & We have documented all actions of the business process to a great extent. & 0,5942 & & 3,959 & & \\
\hline IS3 & During the execution of the process we follow a well-regulated process cycle. & 0,7987 & & 10,9688 & & \\
\hline \multicolumn{2}{|c|}{ Business Process Complexity (BPC) } & & 6.8837 & 0.5085 & 0.8314 & \\
\hline IC1 & The employees executing the business process need to be able to flexible & 0,5117 & & 3,9149 & & \\
\hline $\mathrm{IC} 2$ & The set of inputs necessary for process execution differ often & 0,5046 & & 3,6915 & & \\
\hline IC3 & The business process is characterized by uncertainty & 0,8210 & & 25,2406 & & \\
\hline IC4 & The business process is very complex & 0,8066 & & 23,613 & & \\
\hline IC5 & A lot of information is needed to execute the business process & 0,8374 & & 28,1152 & & \\
\hline
\end{tabular}

